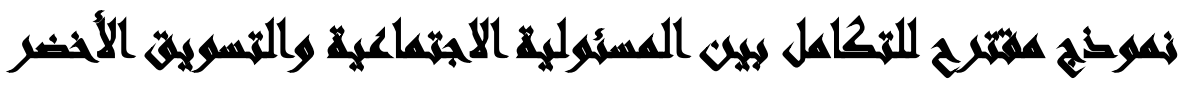

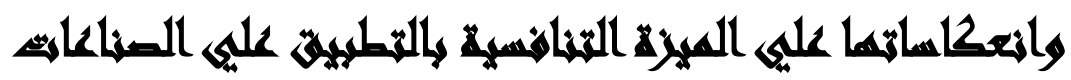

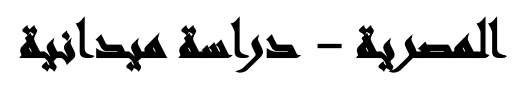

$[r Y]$

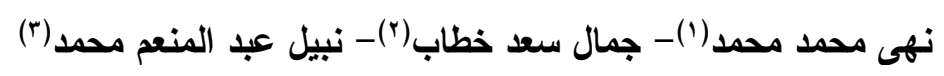

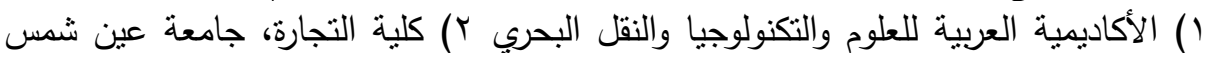
r) المعهد العالي للاراسات التعاونية

\section{المستخلي}

هدفت هذه الدراسة إلى تقديم نموذج مقترح للتكامل بين المسئولية الاجتماعية والتسويق

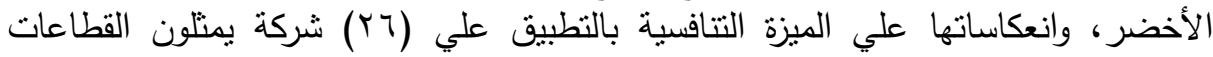

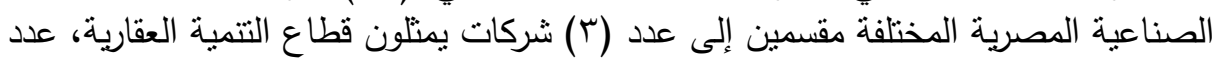

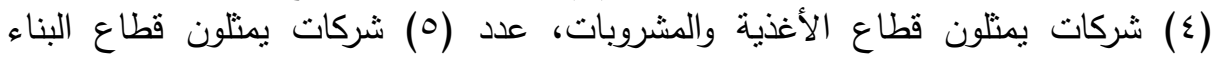

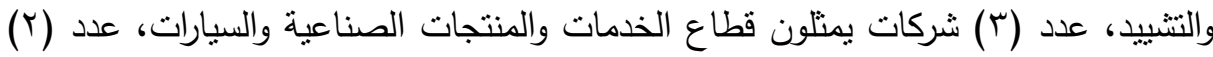

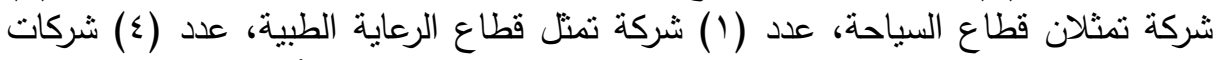

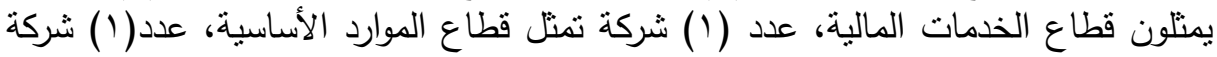

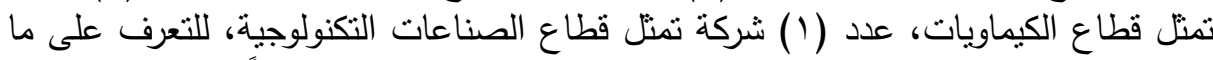

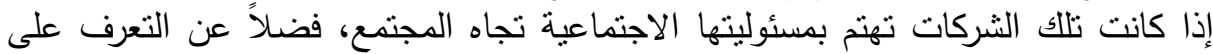

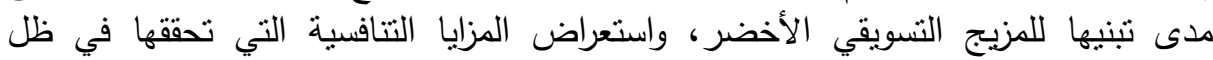

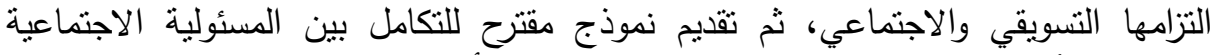

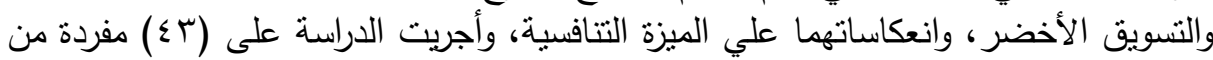

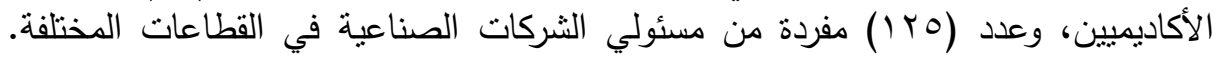

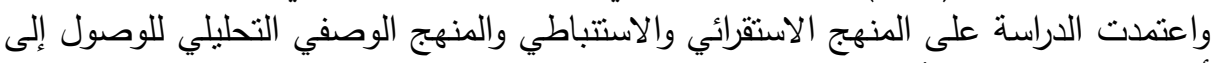

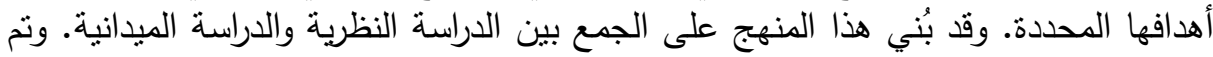
تكوين الإطار النظري من خلال تجميع المادة العلمية المتعلقة بالموضوع محل النّل الدراسة. 
كما اشتملت أدوات الدراسة على استخدام المتوسطات الحسابية، والانحرافات المعيارية،

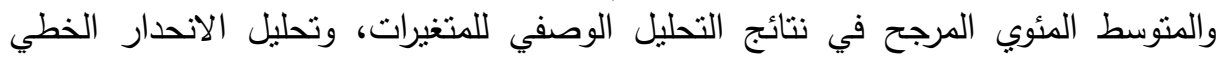

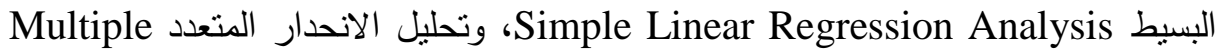

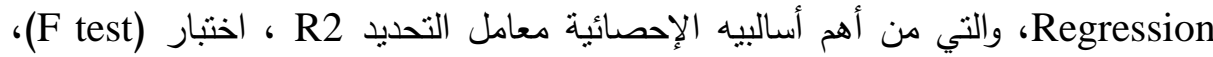
التحليل العاملي التوكيدي Ronfirmatory Factor Analysis CFA، وأسلوب تحليل

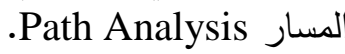

وقد توصلت الباحثون للنتائج التالية: هناك علاقة طردية بين كل مل من المسئولية

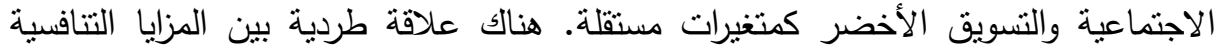

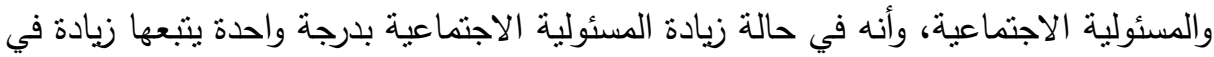

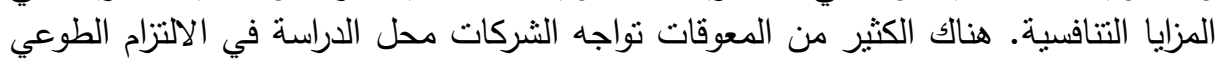

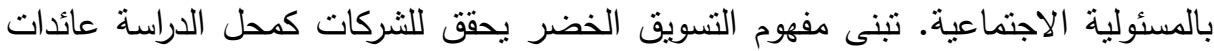
اقتصادية ويحسن من صورة الثركة في نظر العميل ويحقق مزايا تنافسية عدة.

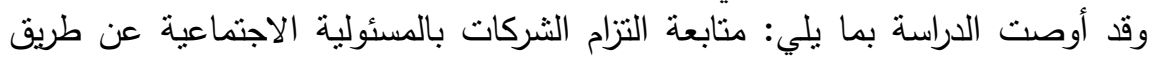

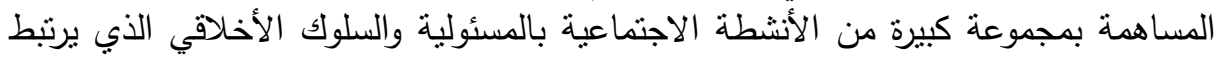

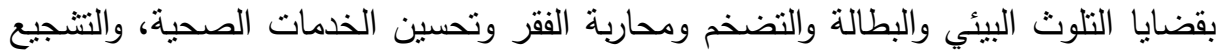

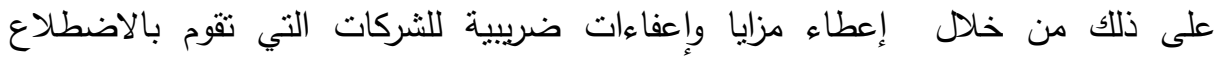

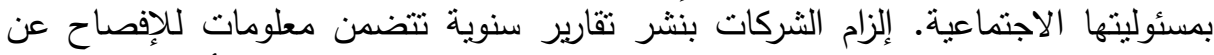

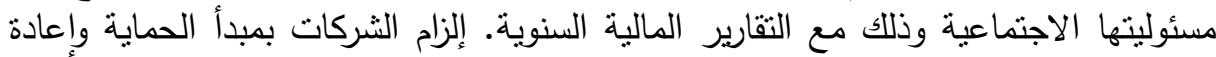

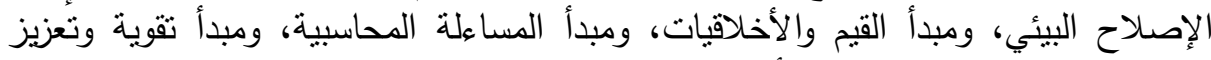

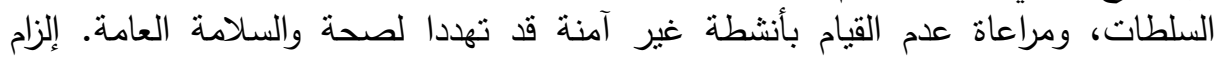

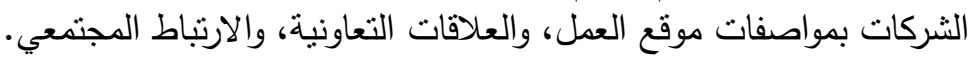

\section{anth}

منذ مطلع الستنيات من القرن الماضي بدأ العالم يبدي انزعاجا وقلقا بالغا حول قضايا

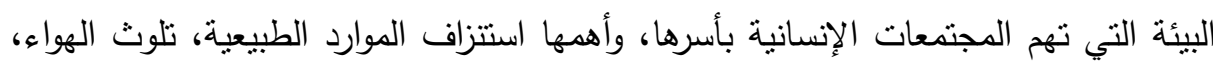
وإنتاج وتسويق سلع ضارة بالبيئة والإنسان، فضلا عن سوء تعامل الإنسان مع البيئة. وظهر ذلك جليا في عدم اهتمام المؤسسات الاقتصادية بتحمل مسئوليتها الاجنماعية تجاه المجمع والبيئة والسير قدما نحو إنتاج منتجات ملوثة للبيئة، والاستمرار في الاعنماد على المزيج التسويقي التقليدي الذي وجهت له الكثبر من الانتقادات بسبب مبالغته في تذليل 
العقبات للزبائن ومحاولة إرضائهم عن طريق إثباع رغباتهم بغض النظر عن الاعتبارات

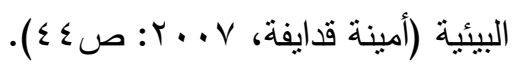

ومن هنا ظهر المفهوم الاجتماعي للنسويق (التسويق الأخضر) الذي يهذف إلى الى الته المحافظة علي التوازن بين المصالح والمنافع للأطراف الثلاثة وهم (الزبائن، والمجتمع، والمنظمة)، والتسويق الأخضر هو عملية تشتنمل علي جميع الأنشطة التسويقية الرامية

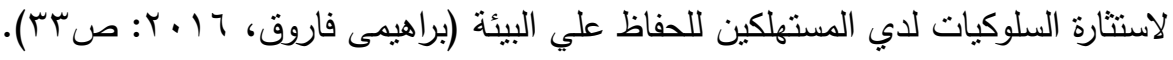
إن الهدف من تبنى المؤسسات الاقتصادية تطبيق مفهوم المزيج التسويقي الأخضر يؤدى

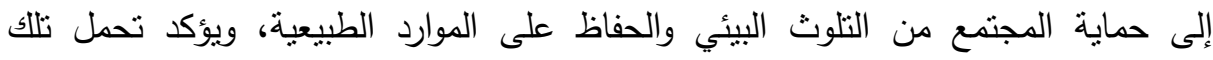

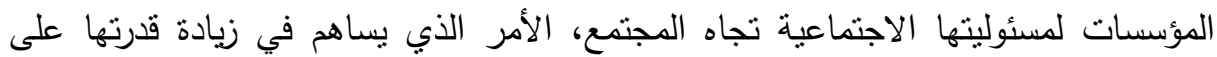
الاستمرار والنمو وتحقيق مزايا تتافسية عديدة، وتحقيق رضا ورغبات العملاء وزيادة معدلات

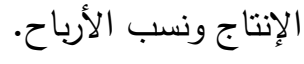

\section{تمساولايته الدواسمة}

يحاول البحث الإجابة على التساؤلات التالية: • ما مدى تأثثير علي المزايا التنافسية في حالة التكامل بين كل من التسويق الأخضر والمسئولية الاجتماعية؟ ماتيز ما الدور الذي يمكن أن يؤدي إلى التزام الثركات الصناعية بالمسئولية الاجتماعية فيما

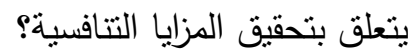
• ما الدور الذي يمكن أن يؤديه تبني الثركات نظام التسويق الأخضر فيما يتعلق بتحقيق

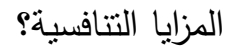




\section{مهاهيه التوراسة}

المسئولية الاجتماعية: هي التزام المنظمات من أجل تعزيز تأثيرها الإيجابي وتقليل تأثيرها

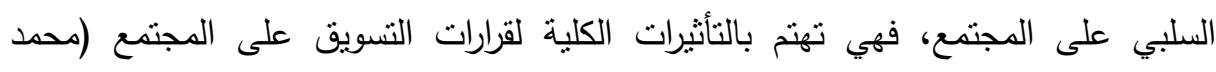

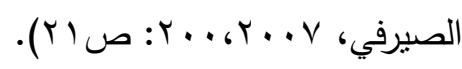
التسويق الأخضر: هو عملية تسويقية متكاملة ومنظمة صمدت للتأثير على تفضيلات

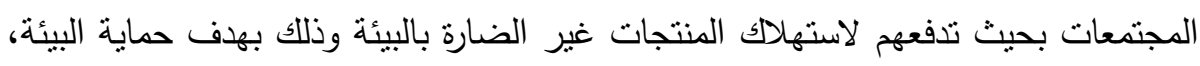

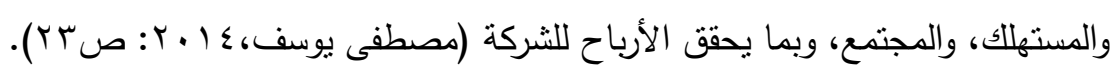
الميزة التنافسية: هي مجال تتمنع فيه المنظمة بقدرة أعلى من منافسيها في استغلال

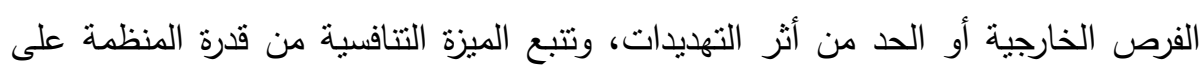

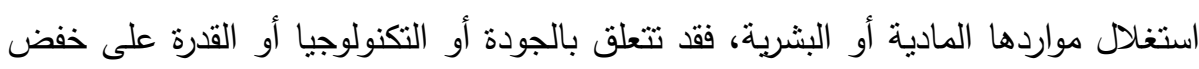

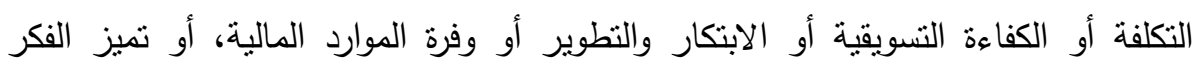

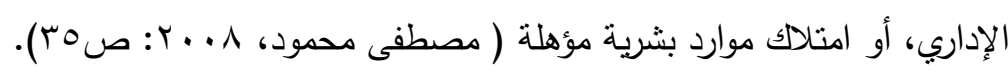

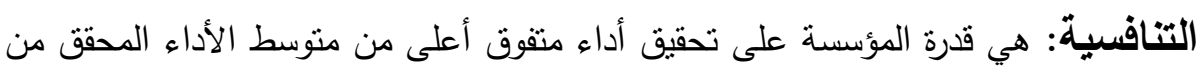

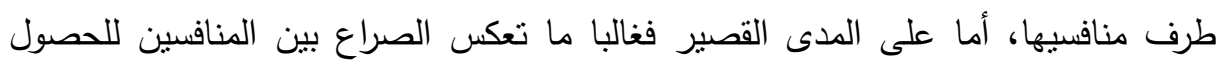

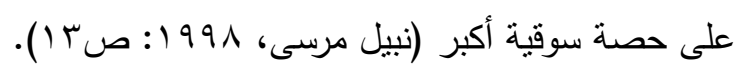

\section{همالح التواسم}

يتجنب المسئولين داخل المؤسسات الاقتصادية والصناعية عدم تبنى فلسفة النسويق

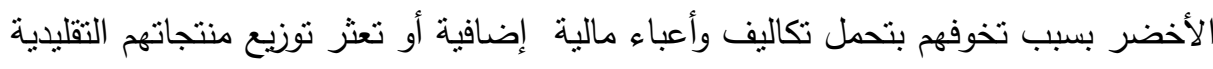

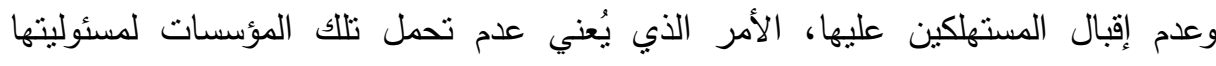

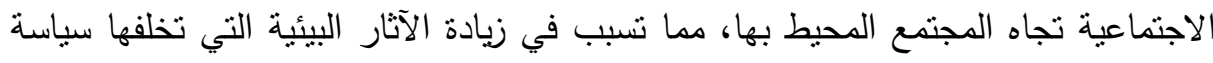

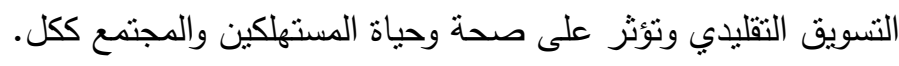


في الوقت التي أكدت فيه العديد من الدراسات الحديثة أن تبنى فلسفة التسويق الأخضر تحقق منافع عديدة منها حماية المستهلكين من النلوث، تحمل المسئولية الاجتماعية تجاه المجتمع، تحقيق مزايا تتافسية عديدة للمؤسسة وزيادة الحصص السوقية وتعظيم الربحية.

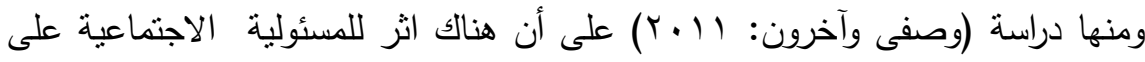
تحقيق ميزة النتافسية حيث تبين أن قطاع كبير من المستهكين مقتتعين بأن الثركة التي

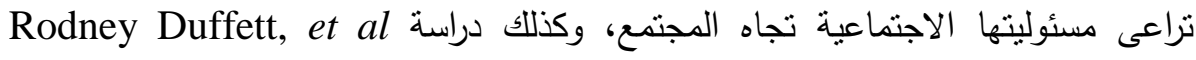
(2018)، التي أكدت أن التسويق الأخضر يحقق مزايا تتافسية عديدة منل التأثير على قرار

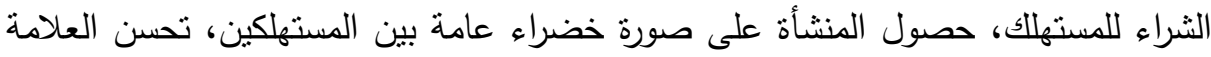
التجارية، تطوير الأعمال الإنتاجية، الاستفادة من إعادة التدوير .

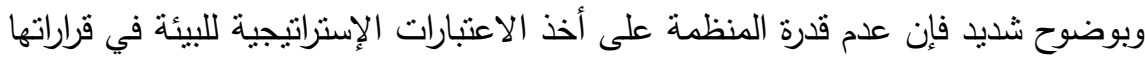
التسويقية تؤثر في استقرارها المالي، وفى قدرتها على المنافسة في السوق الذي تعمل بها، حيث ييلغ حجم الإنفاق على البيئة في بعض الصناعات إلى نحو ـ ب من إجمالي ميزانية

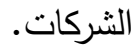
وعليه تبلورت مشكلة الدراسة في التحديات التسويقية التي تواجهها المؤسسات التي ما

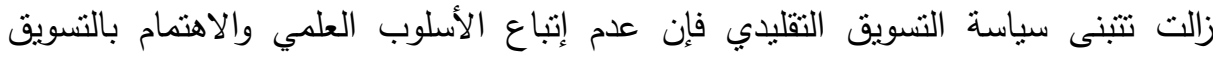
الهادف للحفاظ علي البيئة والمسئولية الاجنماعية للمنشآت، يؤدي إلي ضعف الأداء وعرقلة

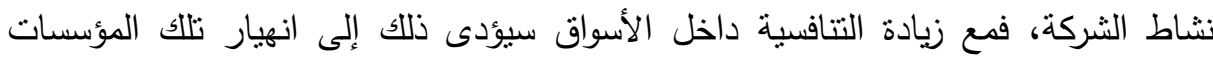

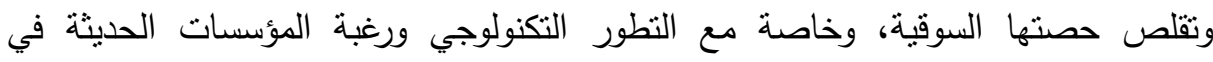
التطوير والابتكار المستمر لاستقطاب وجذب المزيد من المستهلكين، فإذا ما أرادت نلإنك المؤسسات أن تطور من إنتاجها وأسلوبها التسويقي لكسب رضا العملاء لابد من أن تُسرع بتنبي تطبيق مفهوم التسويق الأخضر الذي يهنم بالحفاظ على البيئة وزيادة اهتمامات المؤسسة بمسئوليتها الاجتماعية، فضلا عن تحقيقه لمزايا تتافسية وتسويقية عديدة. 


\section{أهسا هن البوراسة}

• التعرف على مستوى وعي وثقافة المستهلك نحو القضايا البيئية.

• التعرف علي واقع العملي للتسويق الأخضر في المنشآت.

• • دراسة العلاقة بين التسويق الأخضر والمسئولية الاجتماعية.

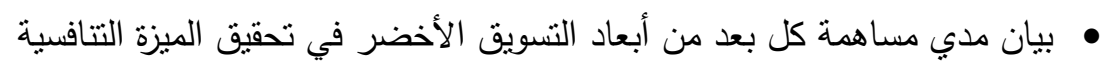

• • • • • براسة العلاقة بين أبعاد التسويق الأخضر والميزة التتافسية.

\section{هزوض القراسلة}

في ضوء مشكلة وأهداف الدراسة يمكن صياغة فروض الدراسة علي النحو التالي: الفرض الرئيس: توجد فروق جوهرية بين الثركات التي لديها إطارا للتكامل بين المسئولية الاجتماعية والتسويق الأخضر، والثركات التي لا تتبنى إطارا للتكامل بين المسئولية الاجتماعية والتسويق الأخضر من حيث تحقيق المزايا التتافسية.

\section{أهمري القواسمة}

تكمن أهمية الدراسة في جانبين هما الجانب العلمي والجانب العملي كما يلي: الأهمية العلمية: تستمد هذه الدراسة أهميتها على المستوى الأكاديمي، وذلك لمحاولتها

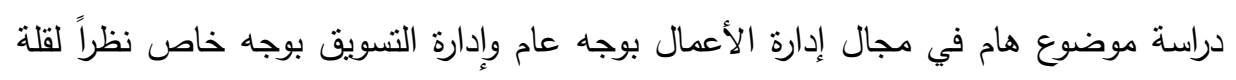

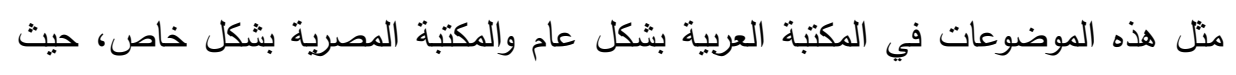

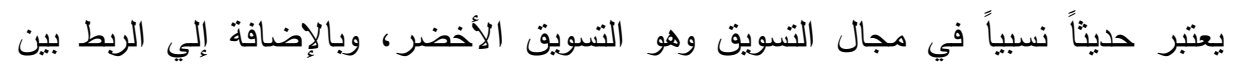
التسويق الأخضر والمسئولية الاجتماعية وانعكاساتهما علي الميزة التتافسية أمر مازال جديداً في البيئة المصرية. الأهمية العملية: تستمد هذه الدراسة الأهمية علي المستوي التطبيقي، وذلك لمحاولتها لتقديم

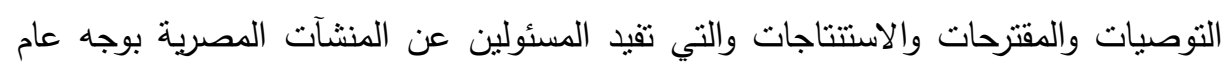
وإدارة التسويق بوجه خاص، مما يساهم في زيادة الميزة التنافسية للمنشآت المصرية. 


\section{السراسايت السابرهي}

دراسة (Claver, E.: 2009): تتاولت الدراسة "دور الإدارة البيئية كعنصر للميزة

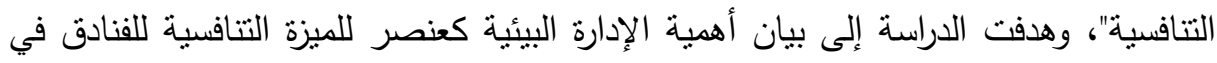

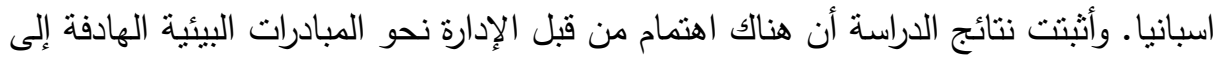

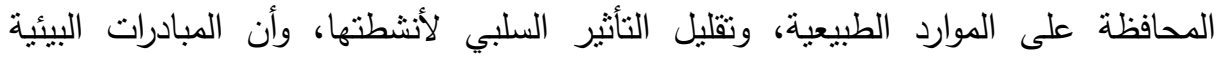

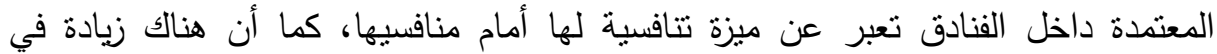
مستوي الأداء ونمو في روح المبادرة البيئية داخل الفنادق. دراسة وصفى وآخرون (11 + Y): تناولت الدراسة اثر المسؤولية الاجتماعية على الميزة التتافسية لثركة الاتصال الفلسطينية من وجهة نظر العملاء-حالة دراسية لثركة جوال. هدفت

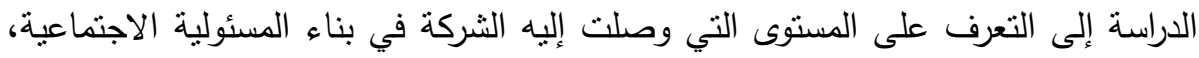

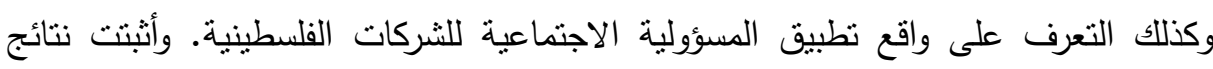
الدراسة انخفاض بعد المسؤولية الاجتماعية تجاه المجتمع من وجهة نظر عينة الأنيات الدراسة حيث

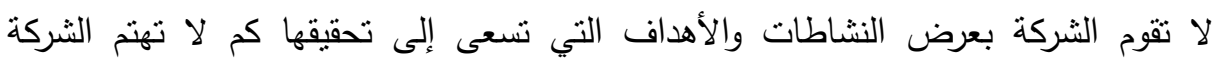

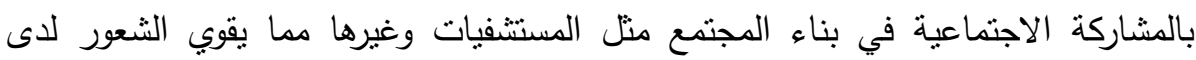

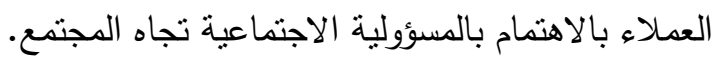
دراسة: (Arifin, Z.: 2012): تناولت الدراسة طبيعة تطبيق التسويق الأخضر

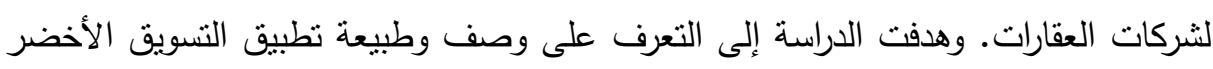

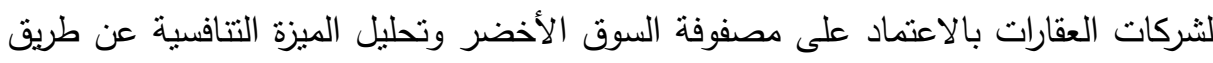

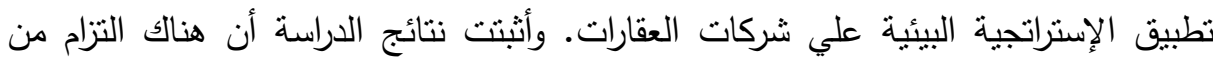

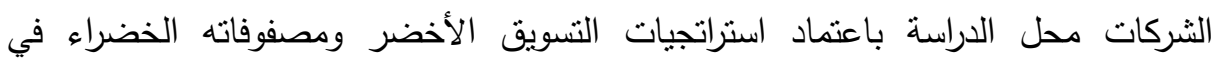

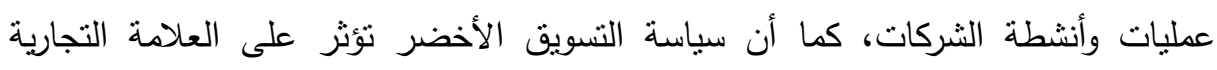
الخاصة بالشركات وصورتها الذهنية أمام زبائنها. 


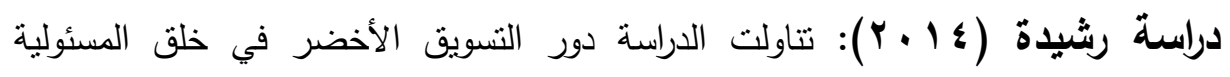

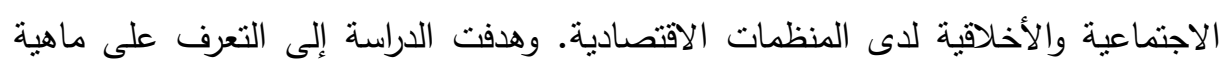

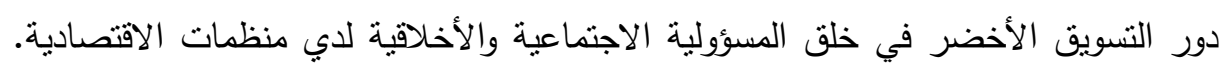

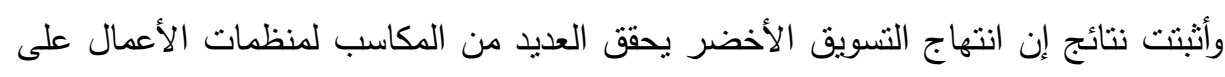

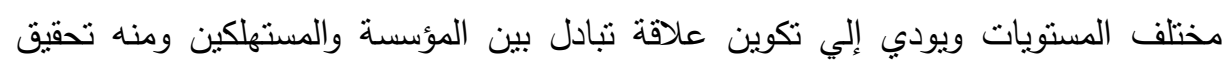

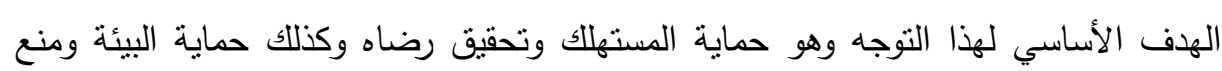

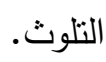

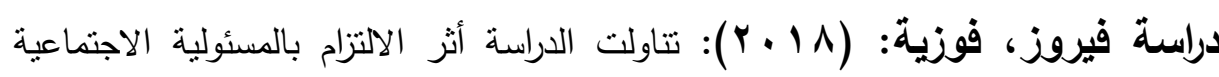

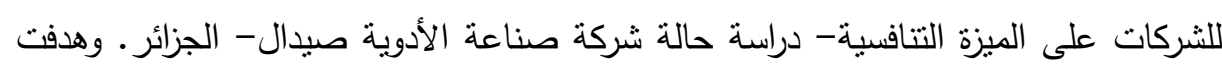

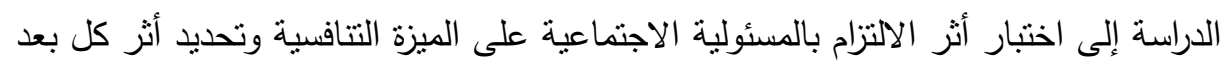

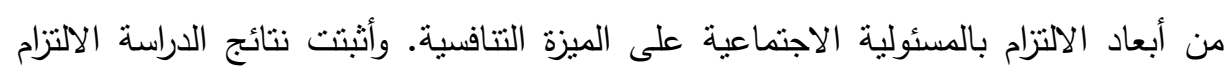

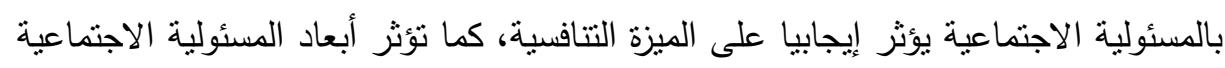
(الأخلاقية- القانونية- الخبرية) إيجابيا على العيزة التنافسية.

\section{الإطار النظايهي}

المسئولية الاجتماعية: يغطي مفهوم المسئولية الاجتماعية ثلاثة مصطلحات، ويربط فيما

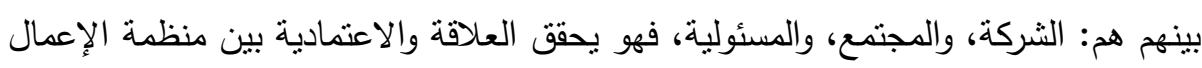

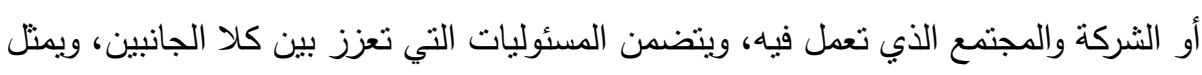

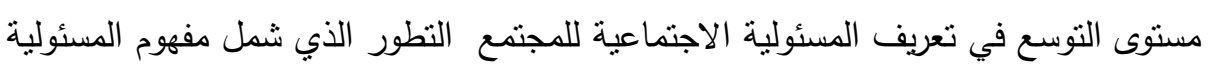

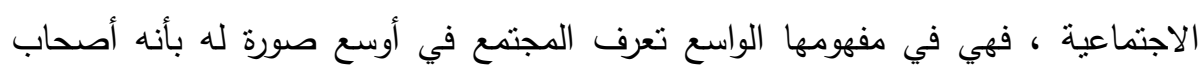

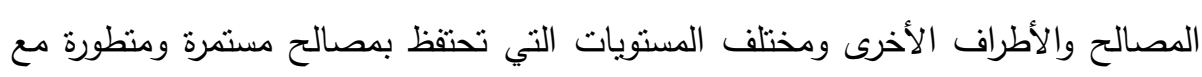
المنظمة (William \& David, 2006: p.6). 
وتعرف المسئولية الاجتماعية بأنها "مبادرات والتزامات المؤسسة والتي لها تأثثر إيجابي

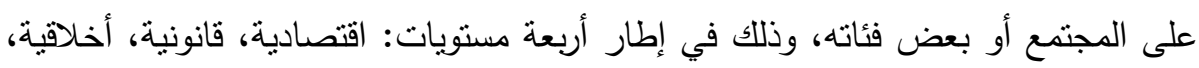

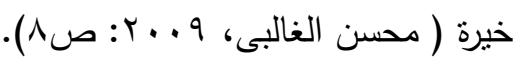
وتتحدد عناصر المسئولية الاجتماعية للمؤسسات في التالي: المسئولية الاجتماعية تجاه المجتمع المحلي: يعتبر المجتمع المحلي بالنسبة للمؤسسات المئية

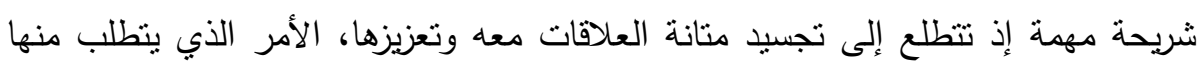

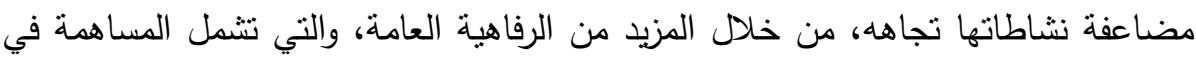

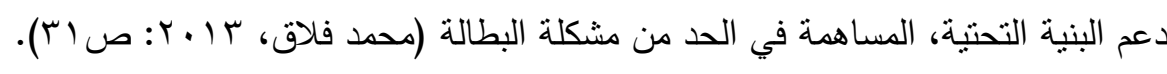
المسئولية الاجتماعية تجاه الموظفين: وذلك من خلال توفير فرص عمل مل متكافئة لجميع

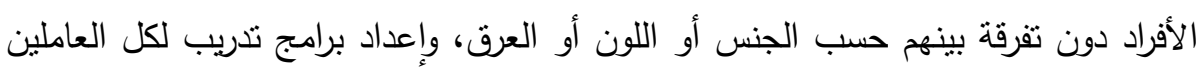

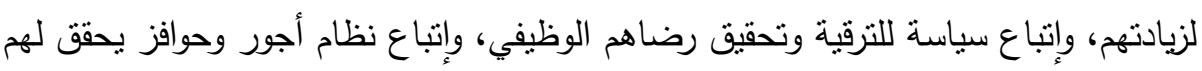

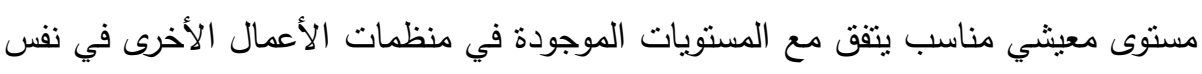

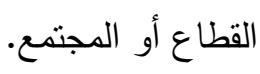
المسئولية الاجتماعية تجاه العملاء: تعتبر هذه الثريحة من المجتمع ذات أهية كبيرة لدى

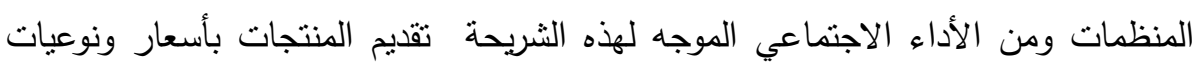

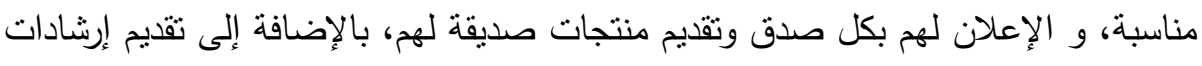

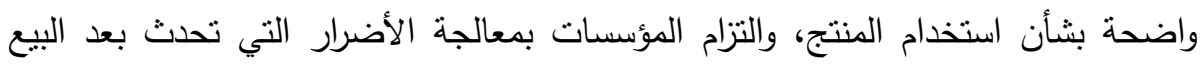

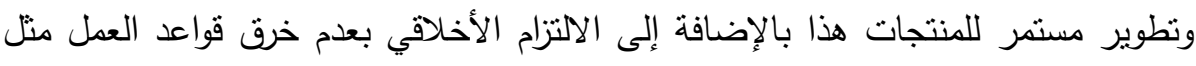

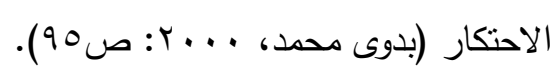

المسئولية الاجتماعية تجاه الموردين: ينظر إلى العلاقة ما بين الموردين ومنظمات الأعمال على إنها علاقة مصالح منبادلة، لذلك يتوقع الموردون أن تحترم منظمات الأعمال تطلعاتهم

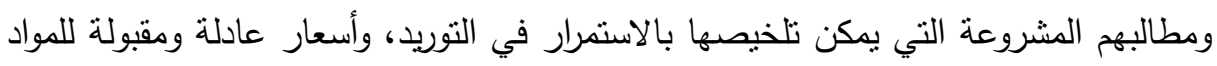

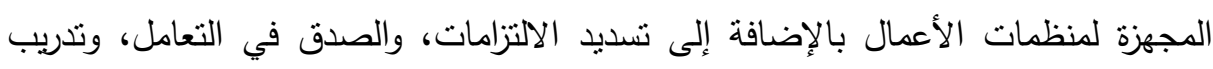
الموردين على مختلف طرق تطوير العمل.

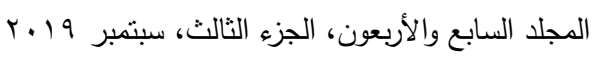


المسئولية الاجتماعية تجاه البيئة: لقد أعبد التركيز في أدبيات المسئولية الاجتماعية فيما

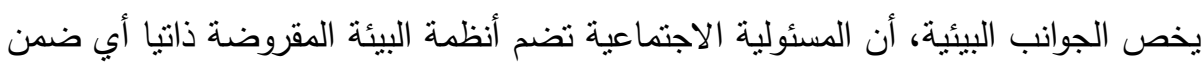

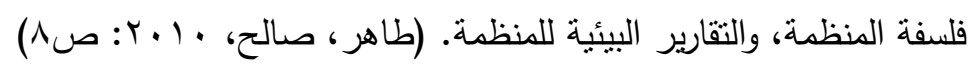
المسئولية الاجتماعية تجاه المساهمين: وتكمن مسئولية المؤسسة تجاههم بتحقيق أقصى لهى

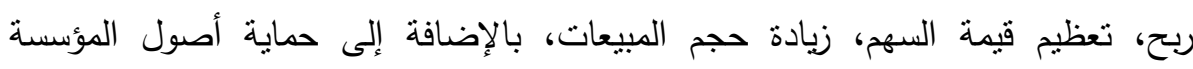

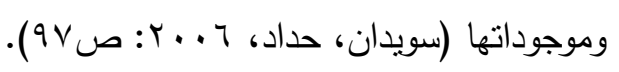

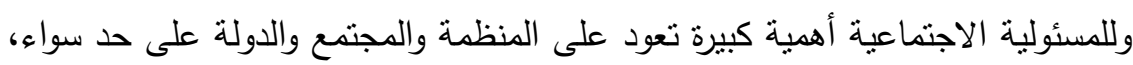
مما يسمح بتجسيد وتعزيز مكانتها في محيط جودتها ويمكن إظهار هذه الأهمية وفق ما يلي: بالنسبة للمنظمة:

- - تحسين صورة المنظمة في المجتمع وترسيخ المظهر الإيجابي لها.

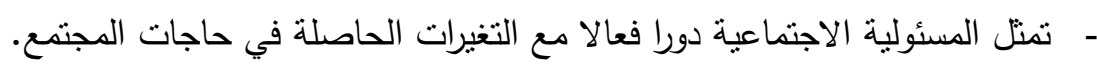
- - خلق توازن بين المنظمة والعاملين لدعم آليات التجديد والابتكار .

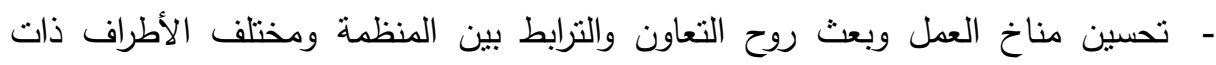
المصلحة.

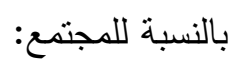
- - حسن إدارة المخاطر الاجتماعية، وهذا بالالتزام البيئي واحترام قوانين العمل والمواصفات القباسية. - مرورة تحسين جودة الحياة في المتمع، سواء من الناحية المادية أو الثقافية، من خلال

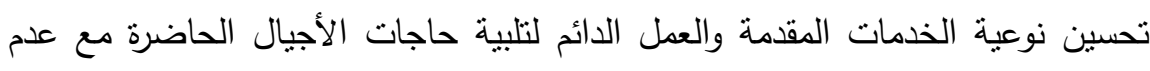
هدر حق الأجيال القادمة. - زيادة التكافل الاجتماعي بين مختلف شرائح المجتمع، مع توليد شعور عال بالانتماء من الإل قبل الأفراد ذوبي الاحتياجات الخاصة، كالمعوقين وقليلي التأهيل والأقليات والمرأة والثنباب. - مكافحة الآفات الاجتماعية منل التسول والتشرد وغيرها. 
بالنسبة للدولة: تتمثل أهم مزايا تطبيق المسئولية الاجتماعية من قبل المنظمات في دعم

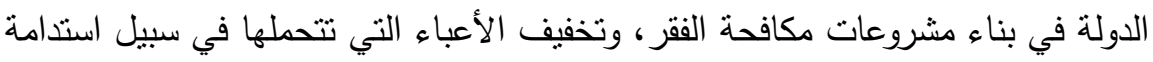

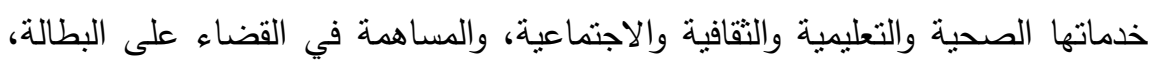

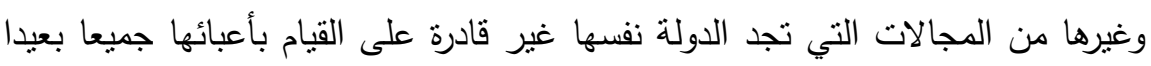

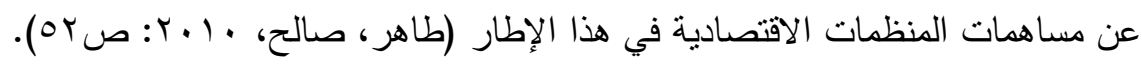

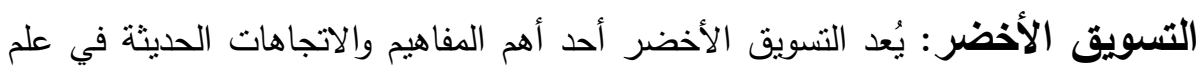
التسويق، وهذا المفهوم غير مألوف لدى العديد من الأشخاص حتى في بعض أوساط العاملين

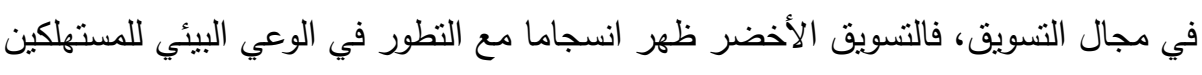

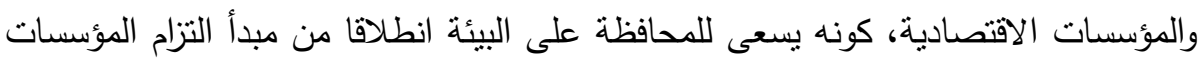
للتعامل مع المنتجات الصديقة للبيئة (Kotler, 2011: p.1). وهناك عدة أسباب للاهتمام بالتسويق الأخضر : • تتاقص المواد الأولية المتواجدة في الطبيعة: ويقصد بذللك المواد غير المحدودة التي تتمثل

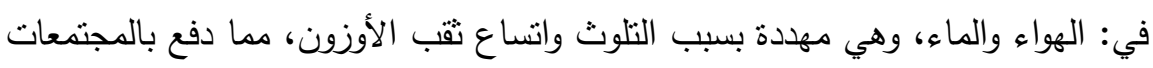
الداعمة للبيئة إلى توحيد جهودها لتحقيق الاستخدام الأمنل لها. • ارتفاع تكلفة الطاقة: ويقصد بذلك ارتفاع تكلفة الطاقة بزيادة أسعارها، ولذلك تنزايد

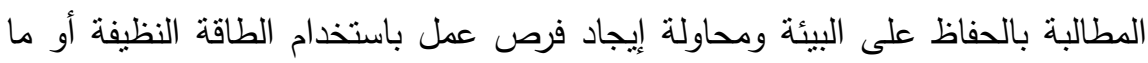

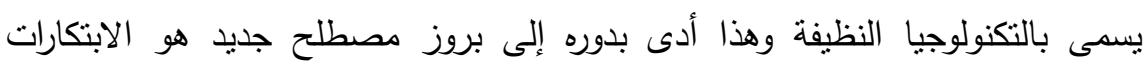
الخضراء أي إيجاد طاقة نظيفة لا تضر بالبيئة.

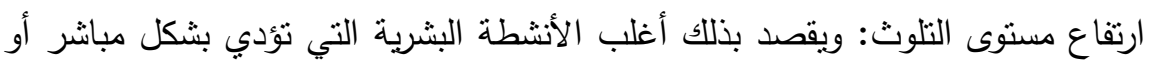

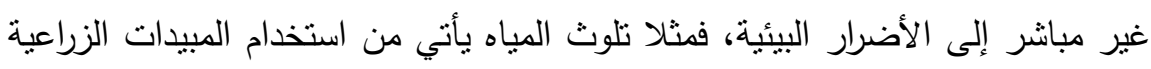

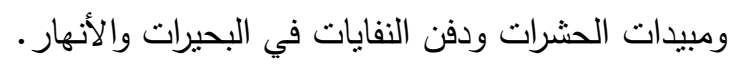
• تحسين سمعة المنظمة: ويقصد بذلك أنن تبني فلسفة التسويق الأخضر يجعل المنظمة قريبة من عملائها وبالذات الذين لايهم توجه بيئي، وكسب وملاء جدد في المستقبل. 
• حسن استغلال الفرص النسويقية: ويقصد بذلك أن التسويق الأخضر يساعد رجال النسويق

على حسن استغلال الفرص التسويقية المتاحة والتأثير في سلوك المستهلك الواعي بئنيأيا.

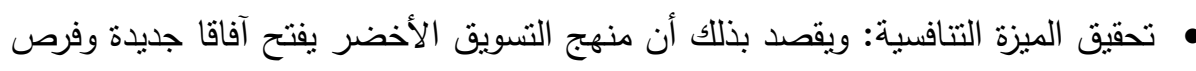

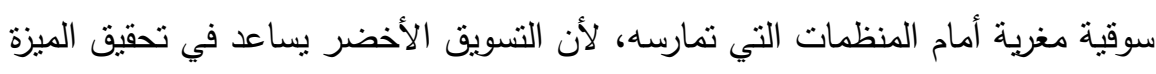
التنافية عن طريق خلق قيم بيئية معينة للعملاء. • تحقيق الأرباح: ويقصد بذلك إن استخدام الأساليب الإنتاجية مرتفعة الكفاءة والتي تعتمد

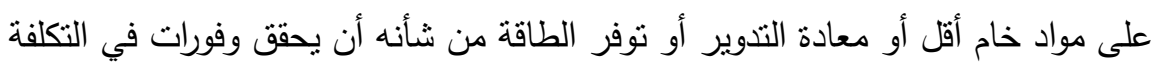

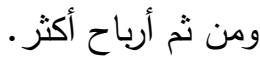
• تحقيق القبول الاجتماعي للمنظمة: ويقصد بذلك الالتزام البيئي للمنظمة يساعد على كسب

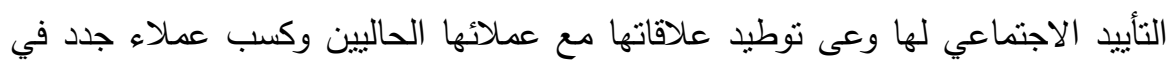
المستقبل.

• إرضاء حاجات المالكين: ويقصد بذلك أن التسويق الأخضر سيفتح أفاقا جديدة وفرص أنفاء

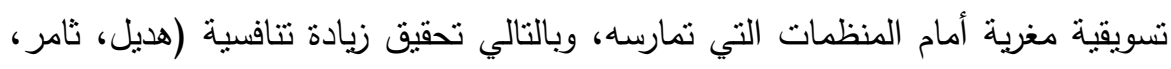

$$
\text { . (rqa } 10
$$

المزايا التتافسية: ينظر إلى المزايا التتافسية بأنها مجموعة من المهارات والتقنيات والموارد

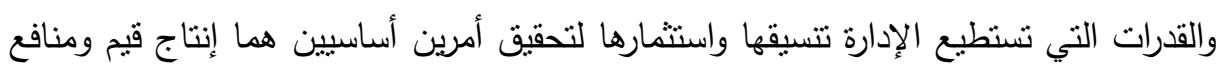

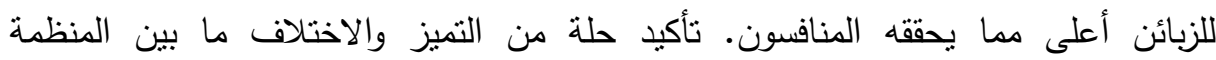

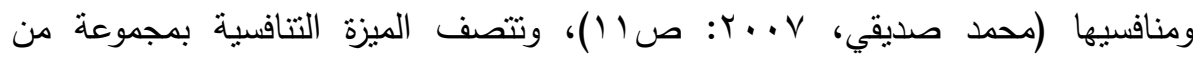

$$
\text { الخصائص المتعددة وهى: وملئ }
$$

- النسبية: فهي ليست مطلقة وتعتمد على المقارنة مع المنافسين في السوق تحقيق الأفضلية، أب التفوق عن المنافسين.

- الاستمرارية والديمومة: بمعنى قابلية المحافظة عليها واستدامتها.

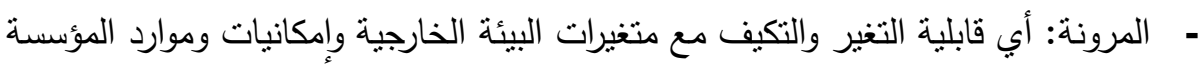
الداخلية. - تحقيق القيمة والمنفعة للعميل وتتعكس نتائجها على المؤسسة. 
- القابلية للتجديد والتطوير وفق منظور استراتيجي أساسه التحسين المستمر من خلال

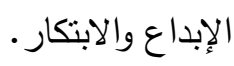

- البعد الاستراتيجي: تركز على المدى البعيد إذ تختص باستغلال الفرص المستقبلية في

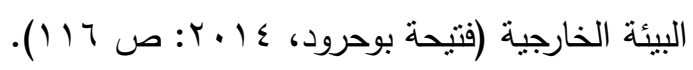

\section{مزايا دمج كل من المسئولية الاجتماعية والتسويق الأخضر والمزايا التنافسية:}

ركز الباحثون من خلال تتاولهم لموضوع الدراسة، على التعرف على ما إذا كانت المؤسسات

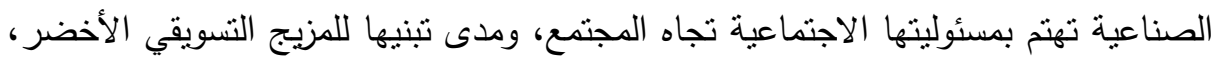

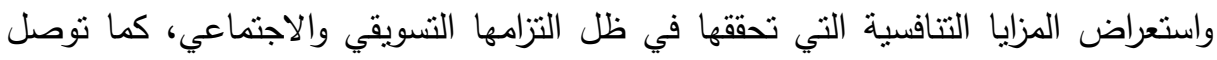

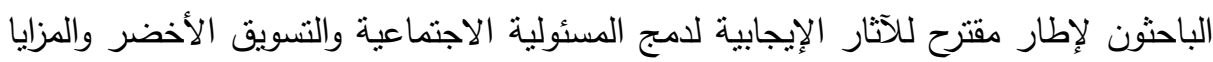

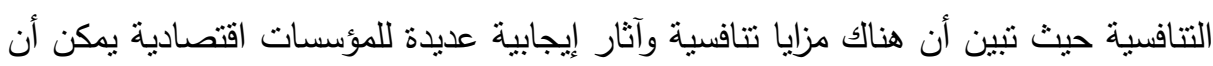

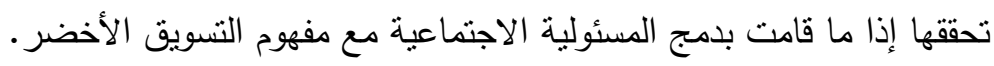

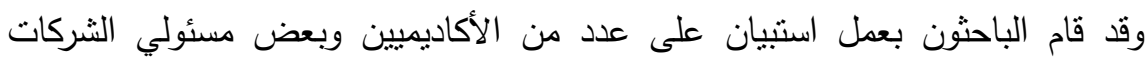

الصناعية في القطاعات المختلفة داخل مصر ، وقد توصلوا إلى عدة نتائج منها: • هناك علاقة طردية بين كل من المسئولية الاجتماعية والتسويق الأخضر كمتغيرات مستقلة.

• هناك علاقة طردية بين المزايا التتافسية والمسئولية الاجنماعية، وأنه في حالة زيادة المسئولية الاجتماعية بدرجة واحدة يتبعها زيادة في المزايا التتافسية.

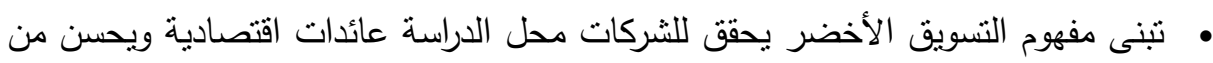
صورة الثركة في نظر العميل ويحقق مزايا تتافسية عدة. ويرى الباحثون أنه نظرا لوجود العلاقة الدالة إحصائيا بين المسئولية الاجتماعية والنسويق وليقاء

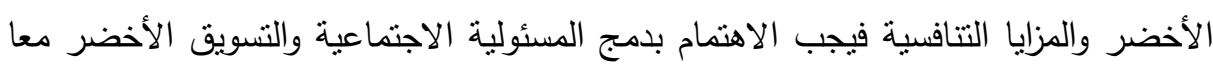

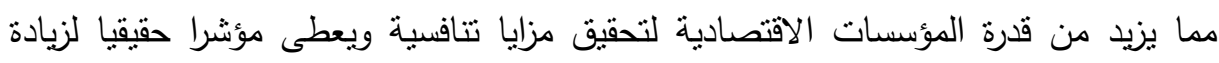


إنتاجيتها وأرباحها، حيث بحقق التسويق الأخضر في حد ذاته نسبة كبيرة في المساهمة في تحقيق البُعد البيئي للمؤسسة.

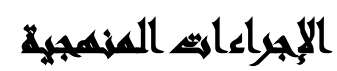

استخدم الباحثون لجمع البيانات، استمارة استنيان، والمقابلات الثخصية، لعينة الدراسة والتي بلغت عينة قوامها (rا) مفردة من الأكاديميون ويشمل ذلك السادة أعضاء هيئة

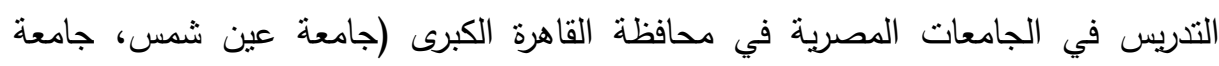
القاهرة، جامعة حلوان) وعدد (Yo ( ) مفردة من مسئولي الثركات الصناعية في القطاعات

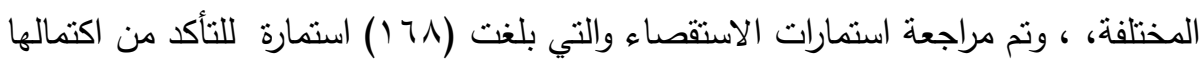

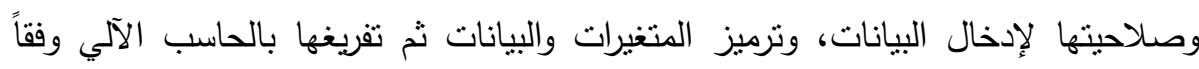

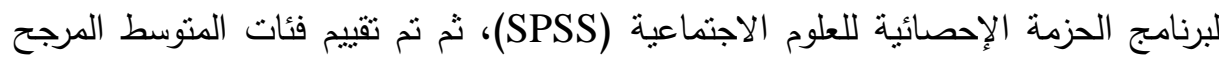

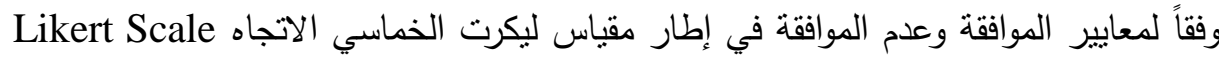
ثم التحليل الاحصائى بواسطة معامل الارتباط لبيرسون.

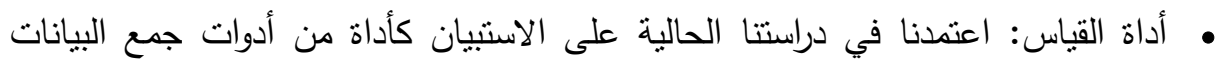
حول الدراسة لذا يعرف الاستبيان على أنه مجموعة من الأسئلة المكتوبة التي توضع الته

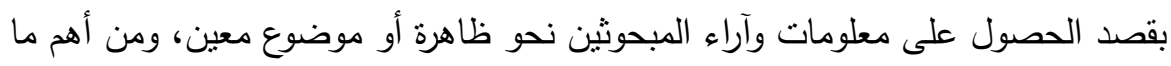
تتميز به الاستبانة هو توفير الكثير من الوقت والجهد وعلى هذا الأساس نم تصميم اسنبيان خاص بموضوع الدراسة مصمم من قبل الباحث، وذلك من أجل جمع البيانات

$$
\text { والمعلومات الخاصة بموضع الدراسة. }
$$

• • صدق وثبات أداة الدراسة: ويشمل وصف أداة الدراسة على صدق الاتساق الظاهري

$$
\text { وثبات وصدق الاتساق الداخلي لأداة الدراسة وذلك على النحو التالي: }
$$

- صدق الاتساق الداخلي: يقصد بصدق الاتساق الداخلي مدى انساق كل عبارة من عبارات لاتل استمارة الاستقصاء مع البعد الذي تتتمي إليه هذه العبارة، وقد قام الباحث بحساب الافي الاتساق

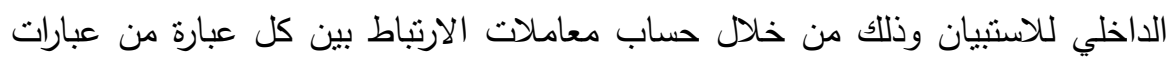
أبعاد استمارة الاستقصاء والدرجة الكلية للبعد نفسه. 
- الصدق البنائي: يعتبر الصدق البنائي أحد مقاييس صدق الأداة الذي يقيس مدى تحقق الأهداف التي نريد الأداة الوصول إليها، ويبين مدي ارتباط كل بعد من أبعاد الدراسة بالدرجة الكلية لكافة الأبعاد.

• ثبات الاستبيان: يقصد بثبات الاستبيان أن يعطي هذه الاسنبيان نفس النتيجة لو تم إعادة

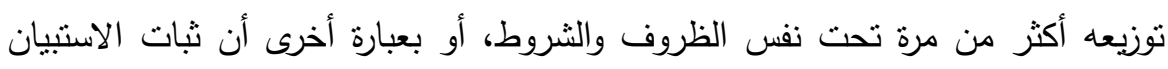

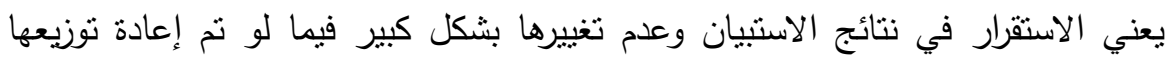

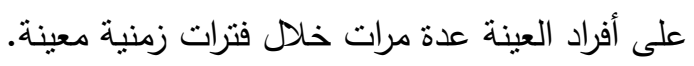
- نتائج ثبات الاستبيان: تحقق الباحث من ثبات استبيان الدراسة من خلال طريقتنين وهما طريقة التجزئة النصفية ومعامل ألفا كرونباخ. - طريقة التجزئة النصفية: نم استخدام درجات العينة الاستطلاعية لحساب ثبات الاستنيان بطريقة التجزئة النصفية، حيث احتسبت بدرجة النصف الأولى لكل بعد من أبعاد

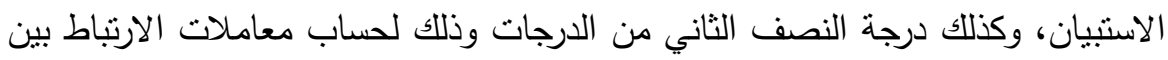

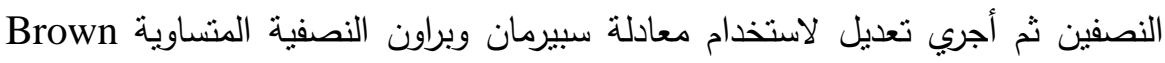
Guttmann Split- Coefficient .Half Coefficient - طريقة ألفا كرونباخ: Alpha Cronbach استخدم الباحثون طريقة أخري من طرق حساب الثبات وهي طريقة ألفا كرونباخ، وذللك بغرض التحقق من ثابت أداة الدراسة، ويعتمد ألفا كرونباخ على حساب تباينات الفقرات وتباين الاختبار .

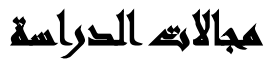

المجال المكاني: تتحدد الحدود المكانية للاراسة الحالية في الجامعات المصرية داخل محافظة القاهرة الكبرى وعدد (Tr) شركة يمثلون كافة القطاعات الصناعية داخل مصر.

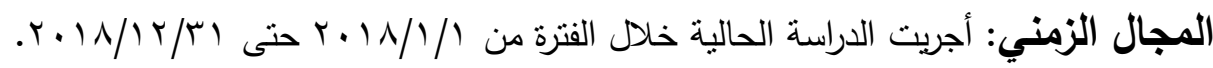


المجال البشرى: أجريت الدراسة على عينة قوامها (بء) مفردة من الأكاديميون ويشمل ذلك السادة أعضاء هيئة التدريس في الجامعات المصرية في محافظة القاهرة الكبرى (جامعة عين الهن

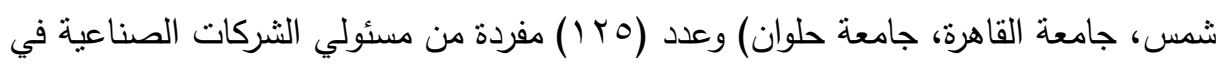

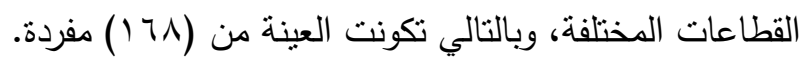

\section{تيتائي السراسة وهنالمشتهما}

وصف نتائج البيانات الأولية لعينة الدراسة:

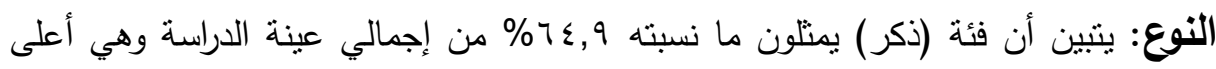

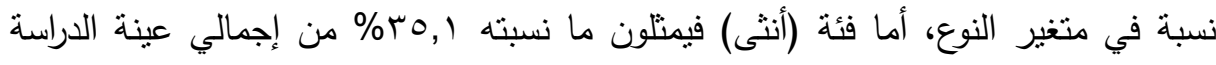

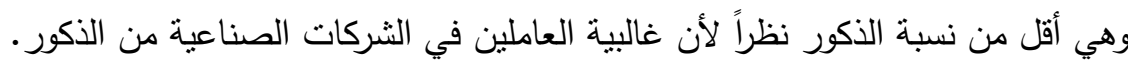

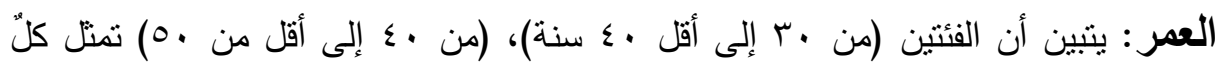

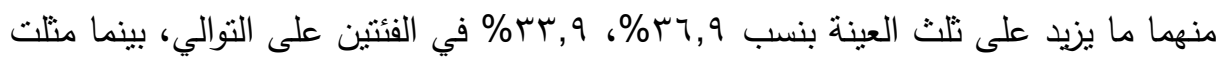

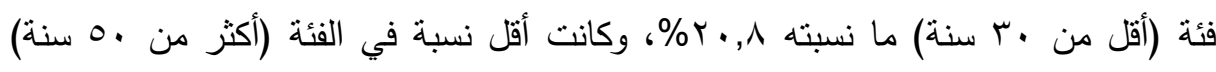

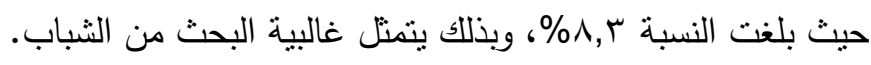
المؤهل العلمي: يتبين أن فئة (بكالوريوس) يمنلون ما نسبته ر,77\% من إجمالي عينة الدراسة وهي أعلي نسبة في متغير المؤهل العلمي، يليها الحاصلين على (دبلوم دراسات عليا)

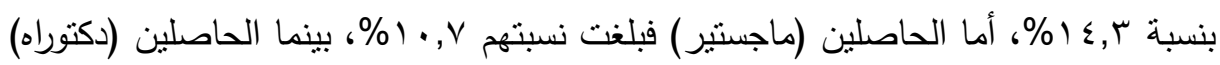

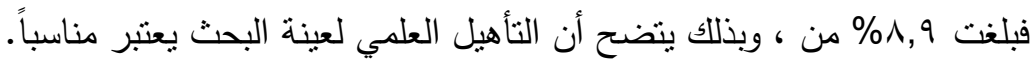

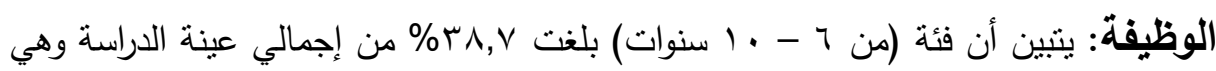

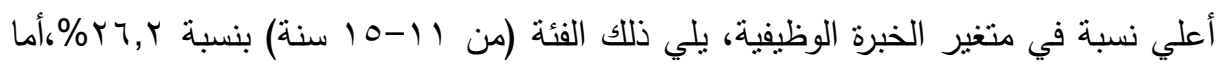

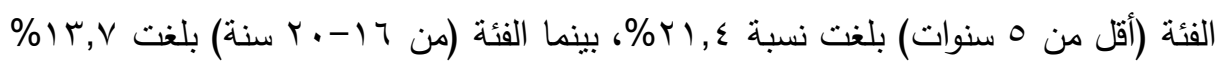

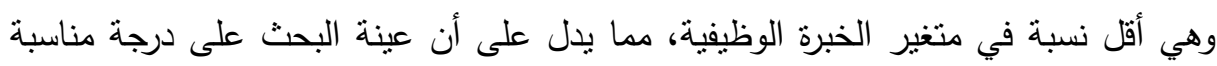
من الخبرة. 
اختبار صحة فروض الاراسة: نم اختبار صحة الفروض التي نم طرحها، وذلك عن

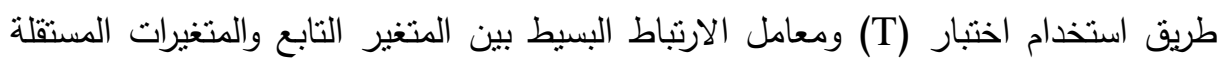

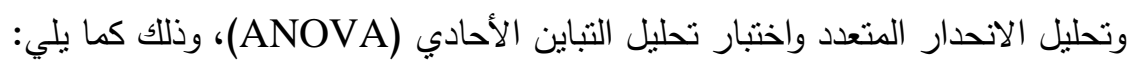

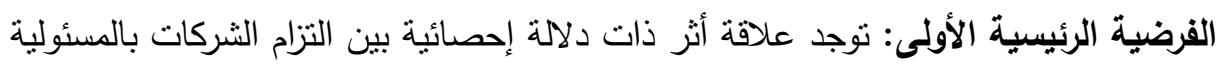

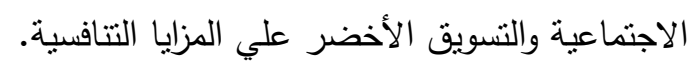

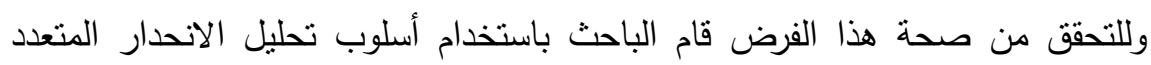

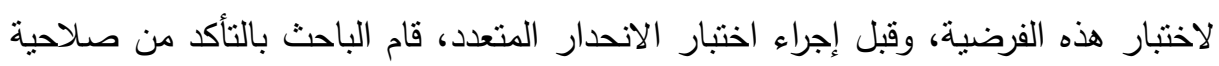
النموذج كما هو موضح في الجدول النالي. جدول (1): نتائج نحليل الانحدار للتأكد من صلاحية النموذج في اختبار الفرضية الرئيسية الأولى : (1)

\begin{tabular}{|c|c|c|c|c|c|c|c|}
\hline \multicolumn{8}{|c|}{ 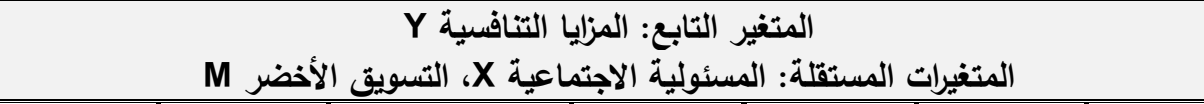 } \\
\hline 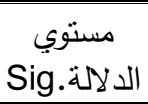 & المسوبة & \multicolumn{2}{|c|}{ معامل الانحدار } & 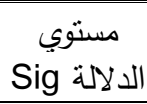 & المسوبة & 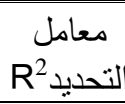 & الارتباط \\
\hline$\cdot, \ldots$ & $r, \wedge / r$ & $\cdot, 099$ & $\alpha$ & \multirow{3}{*}{$\cdot, \cdots$} & \multirow{3}{*}{$r q \wedge, r$} & \multirow{3}{*}{$\cdot$, VAr } & \multirow{3}{*}{$\cdot, \wedge \wedge 0$} \\
\hline$\cdot, \ldots$ & $7,0 \leq 7$ & וזr, & $\beta_{1}$ & & & & \\
\hline$\cdot, \ldots$ & $11, r \vee 0$ & .07. & $\beta_{2}$ & & & & \\
\hline
\end{tabular}

الصصدر : نتائج النحليل الإحصائى

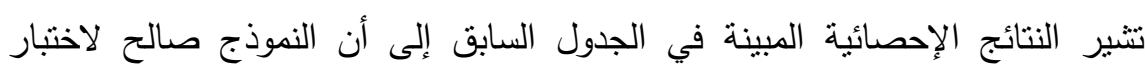

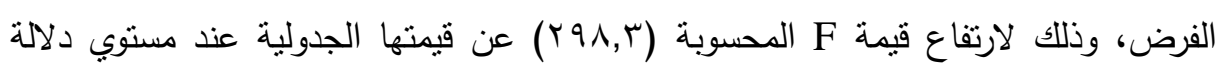

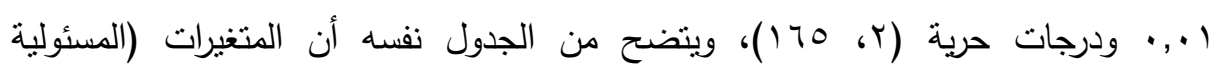

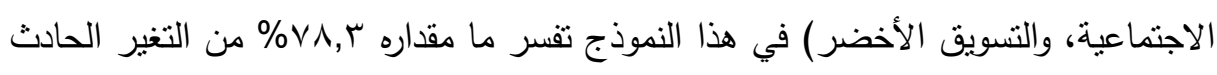

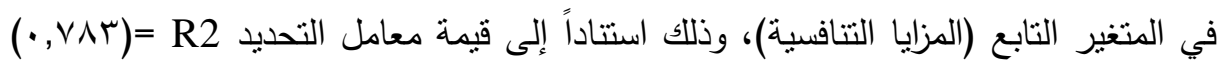

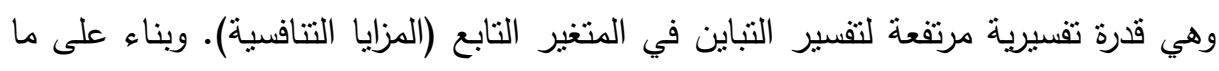


تقدم فأننا نقبل الفرضية الرئيسية الأولي التي تتص على أنه: توجد علاقة أثر ذات دلالة

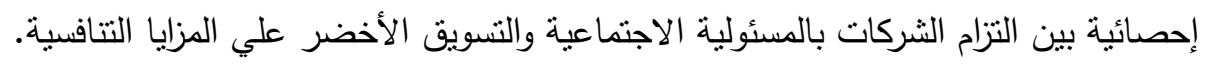

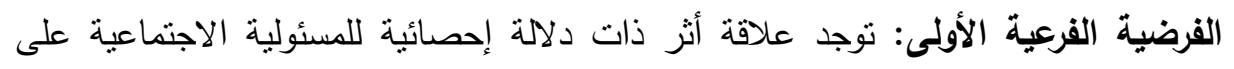

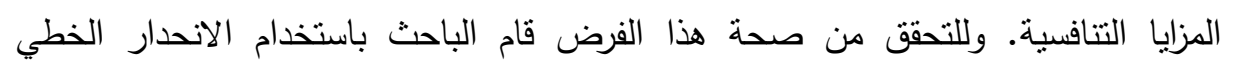
البسيط. جدول (Y): نتائج تحليل الانحدار الخطي البسيط أثر المسئولية الاجتماعبة على المزايا التتافسية

\begin{tabular}{|c|c|c|c|c|c|c|c|}
\hline \multicolumn{8}{|c|}{ 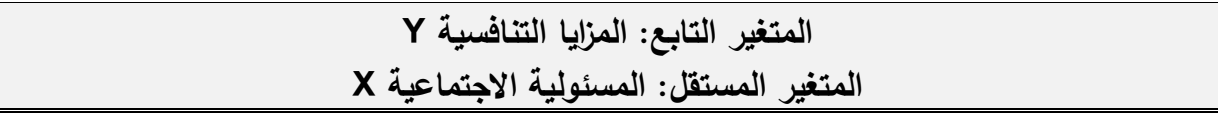 } \\
\hline مستوي & المحسوبة T & \multicolumn{2}{|c|}{ معامل الانحدار } & 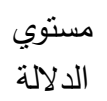 & F المحسوبة & التحديد R2 & الارتباط \\
\hline$\cdot, \ldots$ & $0, M_{1}$ & $1, \cdot V$ & $\alpha$ & \multirow[b]{2}{*}{,$\cdots$} & \multirow[b]{2}{*}{ rฯฯ,V } & \multirow[b]{2}{*}{$\cdot, 717$} & \multirow[b]{2}{*}{$\cdot, \vee \wedge 0$} \\
\hline$\cdot, \cdots$ & سז,7 & $\cdot, V \leq \Lambda$ & $\beta$ & & & & \\
\hline
\end{tabular}

المصدر : نتائج التحليل الإحصائي

تظهر نتائج الجدول السابق وجود أثر للمسئولية الاجتماعية علي المزايا التتافسية، إذ إذئي

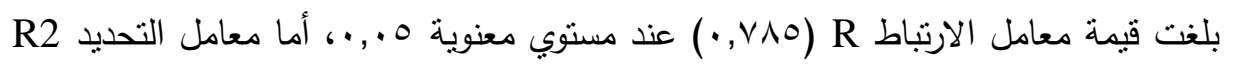

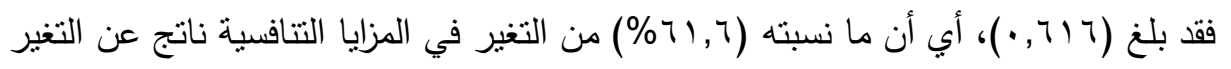

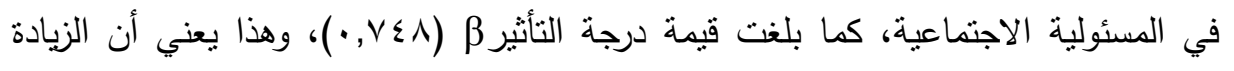
بدرجة واحدة في المسئولية الاجتماعية، يؤدي إلي زيادة في المزايا التتافسية بقيمة قدرها

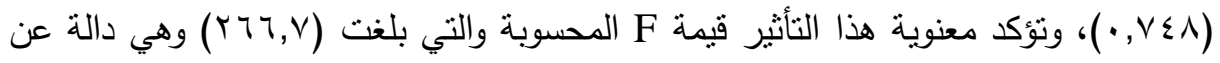

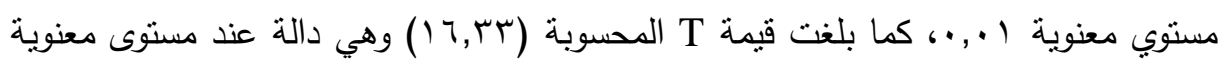

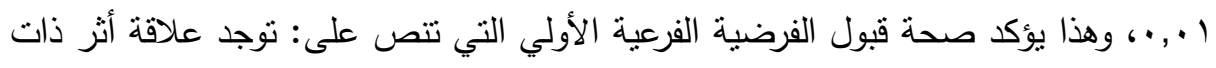
دلالة إحصائية للمسئولية الاجتماعية على المزايا التتافسية.

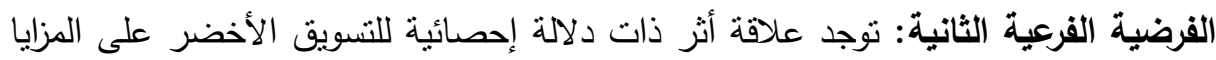
التتافسية. وللتحقق من صحة هذا الفرض قام الباحث باستخدام الاتحدار الخطي البسيط. 
معهد الدراسات والبحوث البيئية - جامعة عين شس لئنس

جدول (r): نتائج تحليل الانحدار الخطي البسيط أثر التسويق الأخضر على المزايا التنافسية

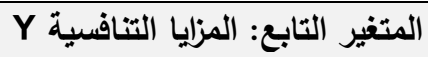

المتغير المستقل: التسويق الأخضر المبنر

\begin{tabular}{|c|c|c|c|c|c|c|c|}
\hline الدلالة. Siتوي Sig & $\begin{array}{c}\text { المحسوبة } \\
\text { T }\end{array}$ & \multicolumn{2}{|c|}{ معامل الانحدار } & الدلالةتوي Sig & المسوبة & التحديد Rعل R2 & $\begin{array}{c}\text { الارنباط } \\
\text { R }\end{array}$ \\
\hline$\cdot, \ldots$ & $7, V \leq V$ & $1, .7$ & $\alpha$ & \multirow{2}{*}{$\cdot, \cdots$} & \multirow{2}{*}{$\varepsilon \varepsilon Y, Y$} & \multirow{2}{*}{$\cdot, V Y V$} & \multirow{2}{*}{$\cdot$, , 04} \\
\hline & $r 1, \cdot r$ & $\cdot, \vee \vee १ \wedge$ & $\beta$ & & & & \\
\hline
\end{tabular}

المصدر : نتائج التحليل الاحصائى

تظهر نتائج الجدول السابق وجود أثز للتسويق الأخضر علي المزايا التتافسية، إذ بلغت

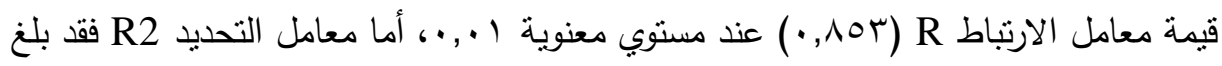

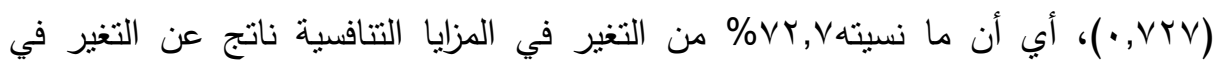

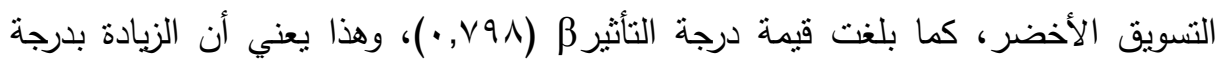

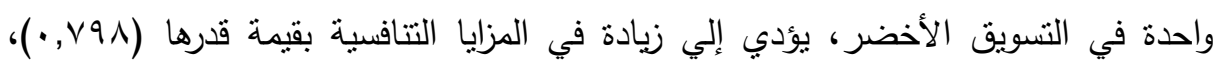

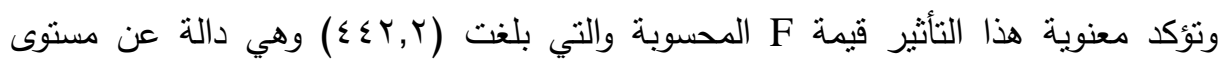

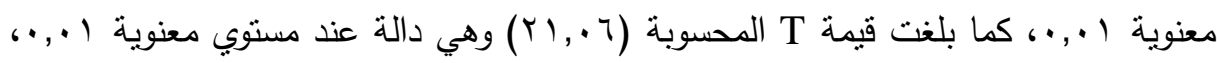
وهذا يؤكد صحة قبول الفرضية الفرعية الثانية التي تتص على: توجد علاقة أثر ذات دلالة إحصائية للنسويق الأخضر على المزايا التتافسية. 


\section{نتائج تحليل المسار Path Analysis:}

Amos Version 23 جدول (ء ): يوضح نتائج اختبار فروض الدراسة باستخدام برنامج

\begin{tabular}{|c|c|c|c|c|c|c|}
\hline $\begin{array}{l}\text { Sig* } \\
\text { الدلالتي }\end{array}$ & $\begin{array}{c}\text { t قيمة } \\
\text { C.R. } \\
\text { الحسوبة }\end{array}$ & الدسار & التأثنير & \multicolumn{2}{|c|}{$\begin{array}{l}\text { Direct Effect } \\
\text { قيمة التأثثر المباشر }\end{array}$} & البيان \\
\hline$\cdot$ & $1 \%, \Lambda$ & $X \rightarrow M$ & \multirow{2}{*}{$\cdot, \varepsilon \mid V$} & $\cdot, V \leq \varepsilon$ & على التسويقيق الأخضاعية & \multirow{3}{*}{ 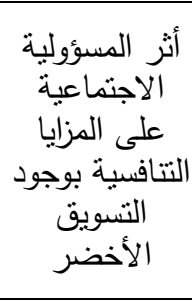 } \\
\hline$\cdot, \cdots$ & $11, r$ & $M \rightarrow Y$ & &., 07. & التسويق الأخضر علية التنافسية & \\
\hline • & 7,7 & $X \rightarrow Y$ & ---- & וTז, • & المسؤولية الاجتماعية المنتافية & \\
\hline
\end{tabular}

المصدر : نتائج التحليل الإحصائي

من الجدول السابق يتضح وجود أثز معنوي للمسئولية الاجتماعية على المزايا التتافسية

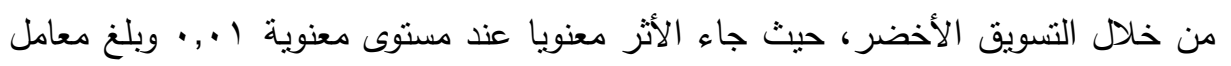

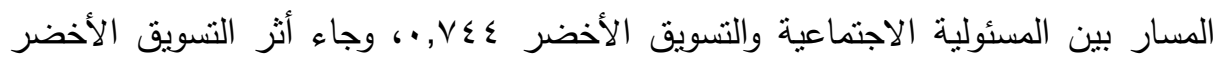

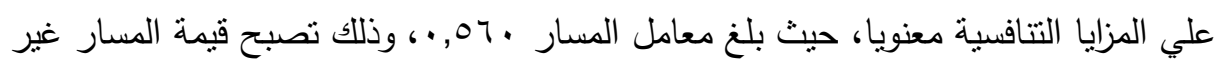

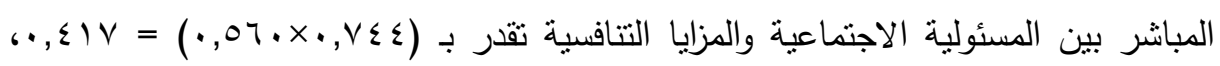

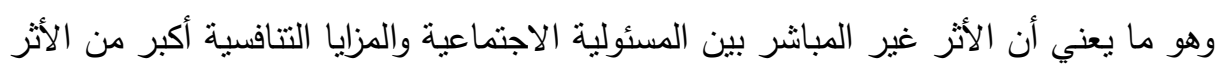

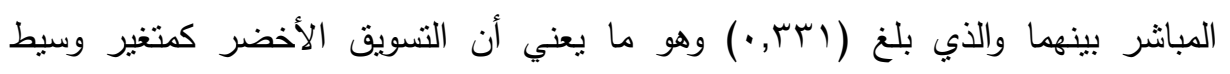

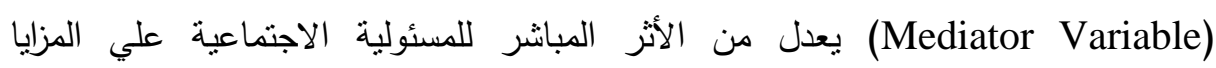
التتافسية، والوساطة هنا وساطة جزئية Partial Mediation وذلك لعدم انتفاء العلاقة بين

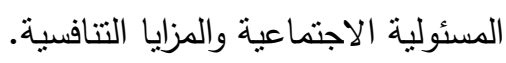

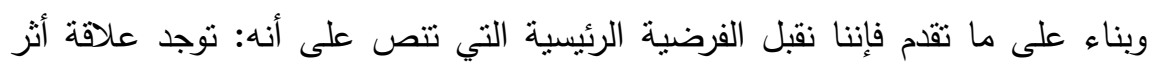

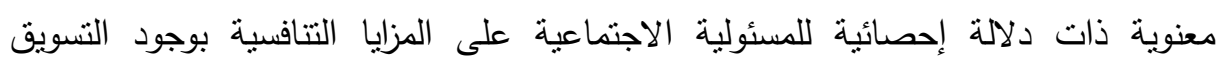
الأخضر كمتغير وسيط. 


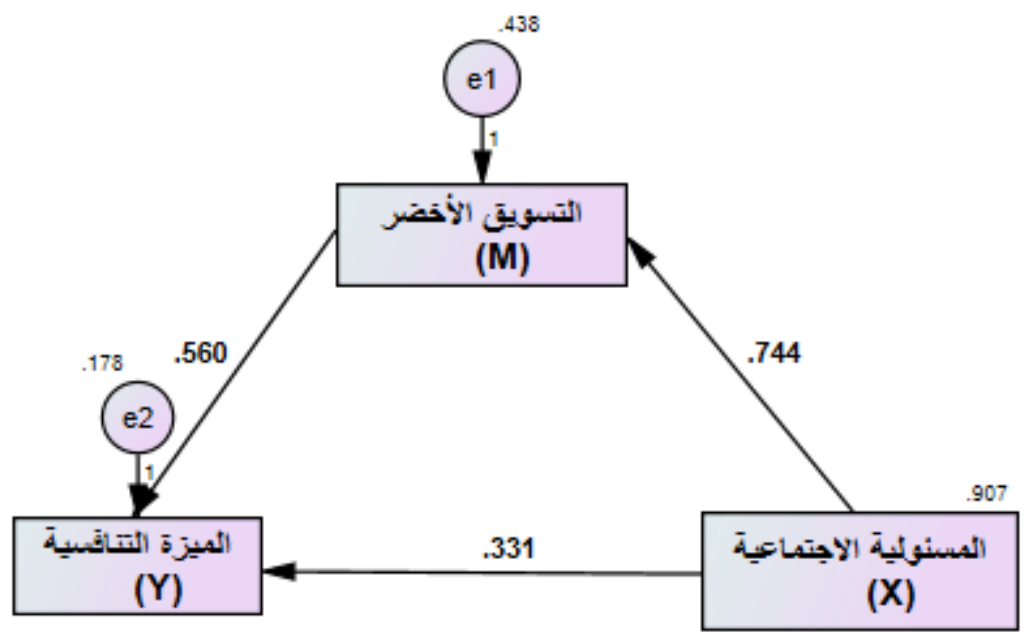

شكل (1): النموذج المقترح للتكامل بين المسئولية الاجتماعية والتسويق الأخضر، وانعكاساتها على الميزة التنافسية

$$
\text { المصدر : نتائج النحليل الإحصائي }
$$

يوضح الثكل أن التأثير المباشر للمسئولية الاجتماعية على الميزة التنافسية اسب, .،

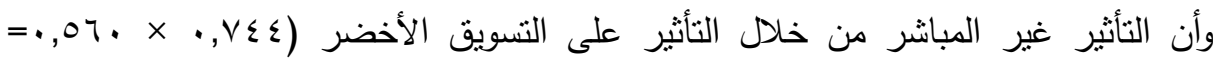

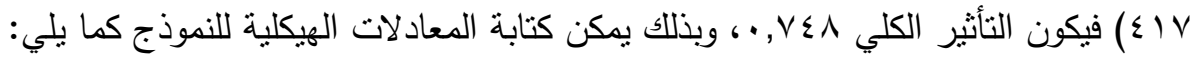
$\boldsymbol{M}=0.840+0.744 * \mathrm{X}+\varepsilon 1$

$\mathrm{R}$ square $=0.534$

$\mathrm{Y}=0.599+0.56 * \mathrm{M}+0.331 * \mathrm{X}+\varepsilon 2$

$\mathrm{R}$ square $=0.783$

حيث X "المسئولية الاجتماعية"، M "التسويق الأخضر "، Y "المزايا التتافسية"، 1ع، 2ع

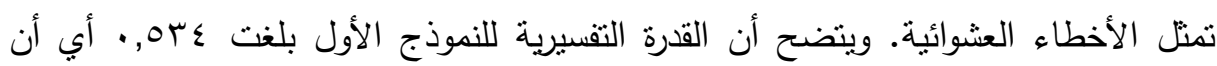

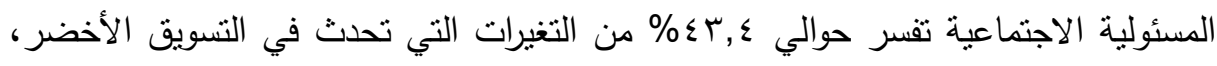

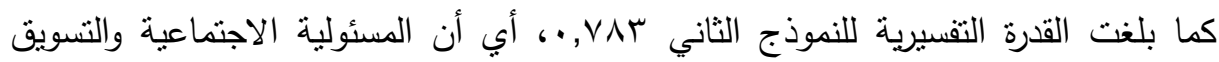

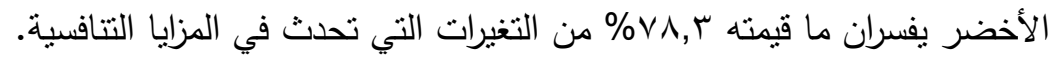




\section{توصلت الدراسة إلى عدة نتائج منها الآتي:}

ا-توجد علاقة أثز ذات دلالة إحصائية بين التزام الثركات بالمسئولية الاجتماعية والنسويق الأخضر علي المزايا التنافسية.

ץ- بوجد علاقة أثز طردية ذات دلالاية إحصائية للمسئولية الاجتماعية على المزايا التنافسية.

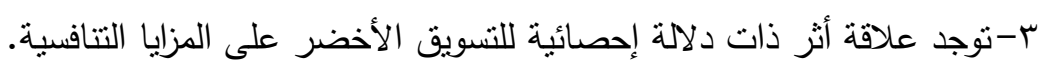
ع-توجد علاقة أثر معنوية ذات دلالة إحصائي للمسئولية الاجتماعية على المزايا التنافسية الإلية بوجود النسويق الأخضر كمتغير وسيط.

0-جاءت تقديرات عينة البحث حول المزايا التنافسية "مرتفعة جداً"، كما جاءت أبعاد الميزة التنافسية مرنبة وفقاً لأهمينه.

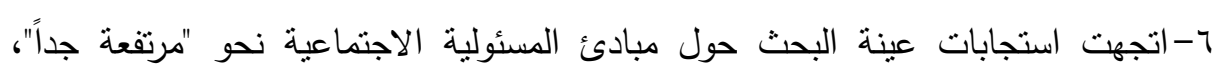

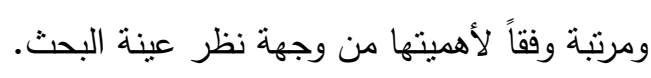
V-جاءت تقديرات عينة البحث "مرتفعة"، كما جاءت أبعاد التسويق الأخضر مرتبة وفقاً لأهميتها.

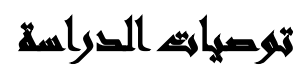

$$
\text { يوصى الباحثون بما يلي: - البي: }
$$

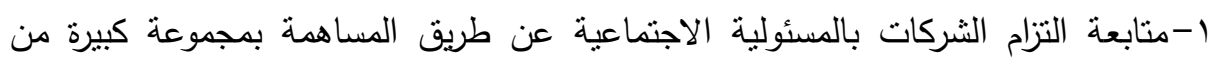

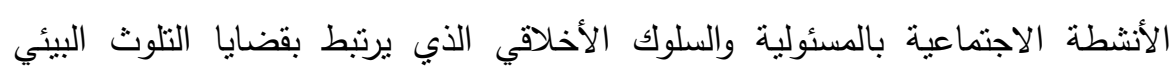

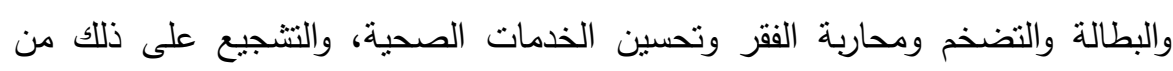

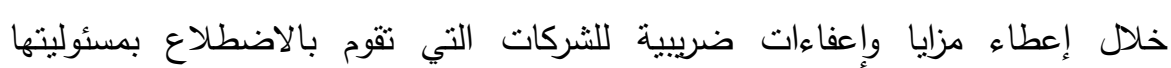

$$
\text { الاجتماعية. }
$$

r- إلزام الثركات بالتسويق الأخضر عن طرق الالتزام بالتعامل مع السلع صديقة البيئة والتي

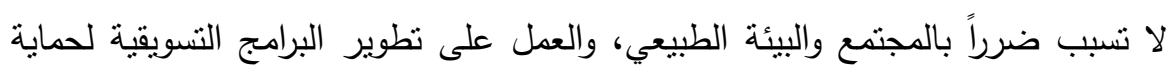
البيئة الطبيعية والمحافظة عليها. 
r-تحقيق أبعاد الميزة التنافسية (البعد الاستراتيجي، البعد التسويقي، البعد الابتكاري) وكذلك العمل على استدامة الميزة التتافسية.

ع-زيادة قدرة الثركات على تلبية الرغبات المختلفة والمتتوعة للمستهلكين وذللك بتوفير منتجات وخدمات ذات جودة معينة و سعر معين بشكل أكثر كفاءة من المنافسين الآخرين في التسويق. البحوث والدراسات المقترحة: من خلال النتائج التي توصلت إليها الدراسة الحالية يقترح الباحثون مستقبلاً إجراء مزيد من الدراسات والبحوث في هذا المجال: 1- مدى مساهمة الالتزام بالمسئولية الاجتماعية في تحقيق التتمية المستدامة. r-فاعلية دمج المسئولية الاجتماعية مع التسويق الأخضر لتحقيق المزايا التتافسية وحماية

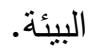
r- أثر التحول من التسويق التقليدي للتسويق الأخضر في تعظيم المزايا التنافسية.

\section{2all}

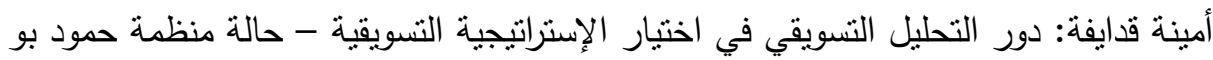

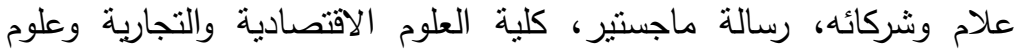

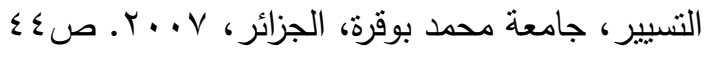

براهيمى فاروق: النسويق الأخضر كمخل لتحقيق الميزة التنافسية بالمؤسسة الاقتصادية

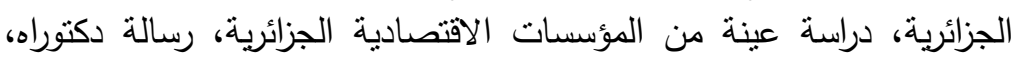

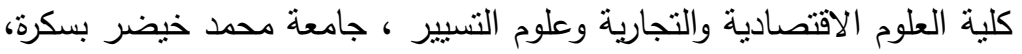

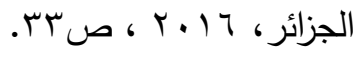

ثامر ياسر البكري: التسويق أسس ومفاهيم معاصرة، دار اليازوري العلمية للنشر والتوزيع،

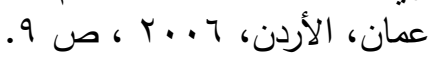

جمال الدين محمد المرسي وآخرون: التفكير الاستراتيجي والإدارة الإستراتيجية، منهج تطبيقي، الإني،

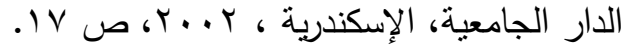




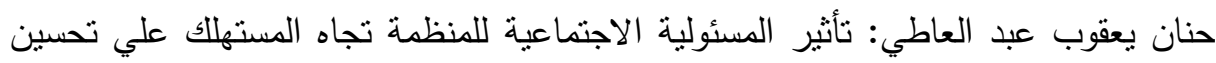

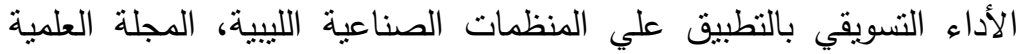

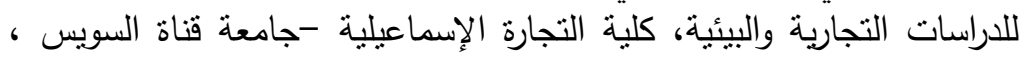

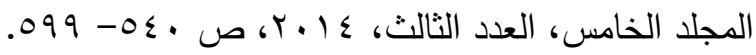

سامي الصمادي: التسويق الأخضر :المعيقات في المنطقة العربية، الملتقى العربي الخامس في الإبي

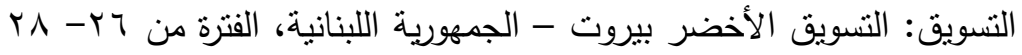

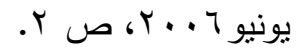

طاهر محسن ألغالبي: إدارة وإستراتيجية،هنظمات الأعمال الصغيرة والمتوسطة، دار وائل

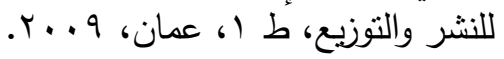

طاهر صالح: الإدارة الإستراتيجية :منظور منهجي منكامل، الطبعة الأولى، دار وائل للنشر

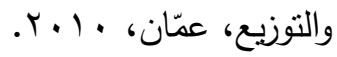

عبد الخالق احمد باعلوي: مبادئ التسويق، الإدارة العامة للمكتبات والتسويق والنشر والتبادل،

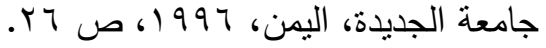

فتيحة بوحرود: إدارة الجودة الثاملة كمدخل لصناعة المزايا التتافسية بين النظرية والتطبيق في

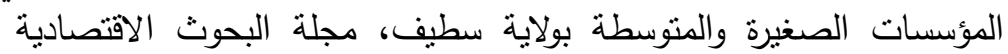

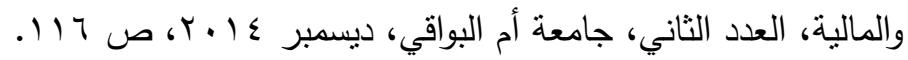

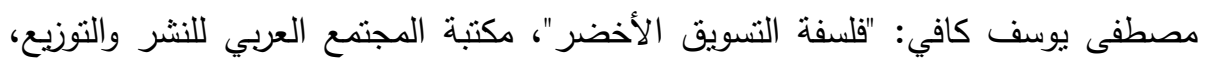

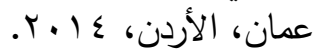

مصطفى محمود أبو بكر : "الموارد البشرية مدخل تحقيق الميزة التتافسية"، الدار الجامعية،

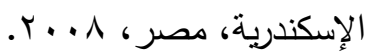

محمد الصيرفي: المسؤولية الاجتماعية للإدارة، دار الوفاء لدنيا الطباعة والنشر، الطبعة

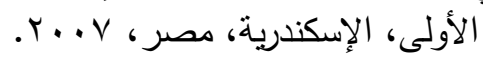

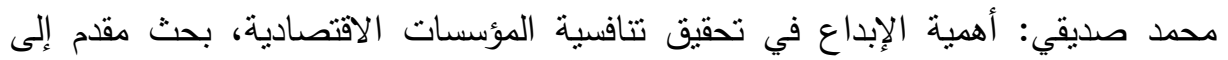

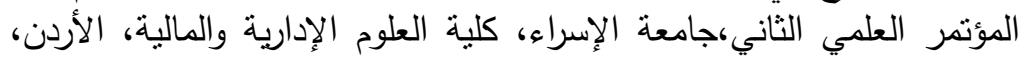
.r...V

مني محمد دكروري: محددات سلوك الشراء الأخضر لطلا الجامعة دراسة تطبيقية علي طلاب

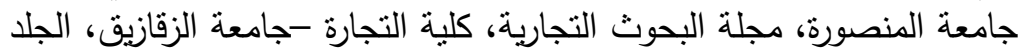
r 


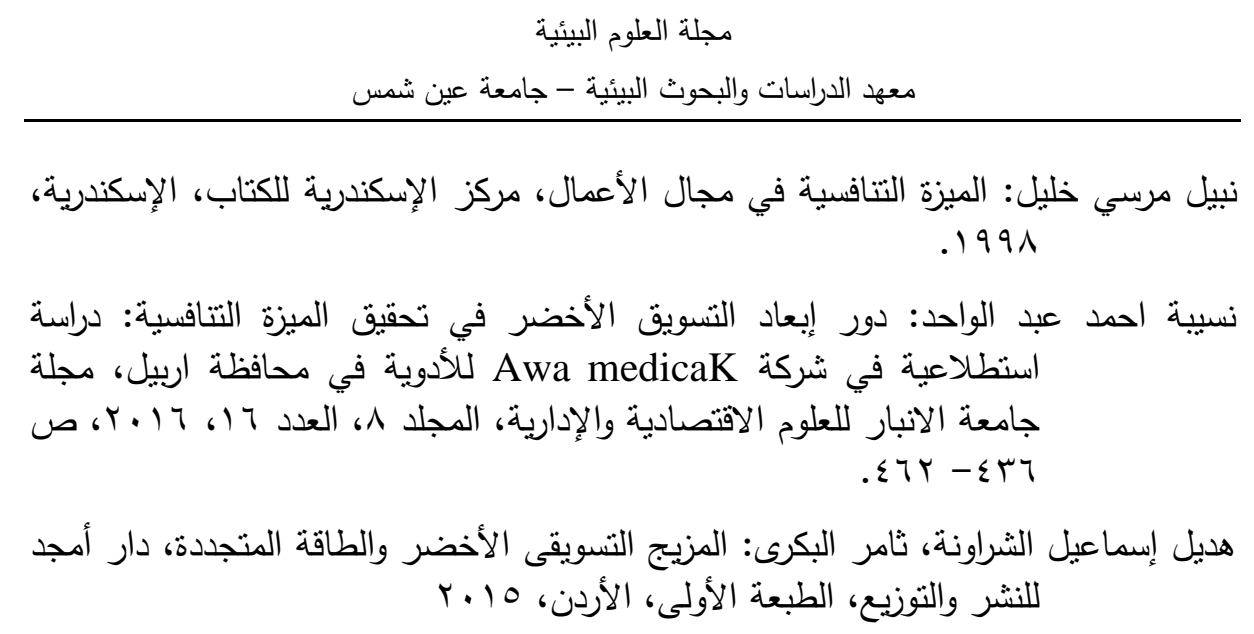

Azzam, Zakaria (2010): Green Marketing: (Concept and Implication). Proceedings of the sixth International Conference, Z.U.

Arifin, Z. (2012): Analysis Of Green Marketing Strategy On Real Estate Company ToAchieve Competitive Advantage: A Case Study Of Ien Nirwana Residence, Malang, East Java. International Journal Of Academic Research, 4(1).

Claver, E. (2009): Environmental Strategies and their impact on hotel performance, Journal of Sustainable Tourism, 15(6), 663-679.

Kotler P. (2011): Reinventing marketing to manage the Environmental Imperative. Journal of Marketing, 75(4), 132-135.

Fraj E. and Matute J. (2011): Green Marketing Strategy And The Firm's Performance: The Moderating Role Of Environmental Culture. Journal Of Strategic Marketing, 19(4), 339-355.

Jean-Louis Muchiell: La compétitivité : définition, Indicateurs et Déterminants, site : team.univparis1.fr/teamperso/mucchiel/ competitivite.pdf. Date: 2002. P.9.

Pride, William and Ferrell (2003): Marketing Concepts and Strategies. 12 ${ }^{\text {th }}$ ed., Houghton Mifflin Company. 
نهى محمد محمد وآخرون

\title{
PROPOSED FRAMEWORK FOR THE \\ INTEGRATION BETWEEN THE SOCIAL \\ RESPONSIBILITY AND THE GREEN MARKET \\ AND ITS REFLECTION ON THE COMPETITIVE \\ ADVANTAGE \\ CASE OF EGYPTIAN INDUSTRIES
}

[22]

\author{
Noha. M. Mohamed ${ }^{(1)}$; Gamal S. Khattab ${ }^{(2)}$ \\ and Nabil A. Mohamed ${ }^{(3)}$
}

1) Post-graduate student at Institute of Environmental Studies and Research, Ain Shams University 2) Faculty of Commerce, Ain Shams University 3) Higher Institute of Co-operative and Managerial Studies

\begin{abstract}
This study aimed at presenting a proposed model for the integration of social responsibility and green marketing, and its implications on the competitive advantage of applying to the Egyptian industries for the number of (26) companies representing the different sectors of the Egyptian industry divided into the number of (3) companies representing the development sector Al-Aqaria, Number of (4) companies representing the food and beverage sector, number (5) companies representing the construction sector, number (3) companies representing the services sector, industrial products and automobiles, number (2) company representing the tourism sector, number (1) company representing the medical and health care sector, number (4) companies representing Financial services sector other than banks, number (1) company representing the core resources sector, number (1) company representing the chemical sector, number (1) company representing the sector of technological industries, to determine whether those companies are interested in their social responsibility towards the community, as well as to identify the extent of their adoption to mix the

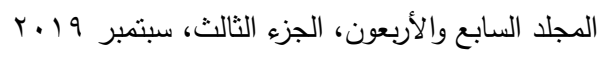


green catalog, and to review the competitive advantages and environmental benefits that these companies achieve in the context of their marketing and social commitment, then submit a proposed model for the integration of social responsibility and green marketing, and their implications on the competitive advantage, and conducted the study on (168) One of the officials in the form of (43) individual faculty members of the Egyptian universities in the Greater Cairo Governorate (Ain Shams University, Cairo University, Helwan University) and the number of (125) Individual officials of industrial companies in various sectors. The study relied on the inductive approach and the analytical descriptive approach to reach its specific objectives, this approach was built to combine theoretical study and field study and the theoretical framework was formed by compiling the scientific material on the subject under study. 